\title{
CrystEngComm
}

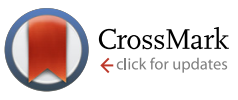

Cite this: CrystEngComm, 2017, 19, 469

\section{Towards understanding intermolecular interactions in hydantoin derivatives: the case of cycloalkane-5-spirohydantoins tethered with a halogenated benzyl moiety $\dagger$}

\author{
Anita Lazić, ${ }^{a}$ Nemanja Trišović, ${ }^{\star a}$ Lidija Radovanović, ${ }^{b}$ Jelena Rogan, ${ }^{a}$ Dejan Poleti, ${ }^{a}$ \\ Željko Vitnik, ${ }^{c}$ Vesna Vitnik ${ }^{c}$ and Gordana Ušćumlićc
}

\begin{abstract}
A series of cycloalkane-5-spirohydantoins bearing a halogeno substituted benzyl group $(\mathrm{X}=\mathrm{Cl}$ and $\mathrm{Br}$ ) in position 3 has been synthesized and their structures (1-6) have been determined by a single crystal $X$-ray diffraction method. These compounds have multiple functional groups, which allow greater competition and/or cooperation among the different intermolecular interactions in the formation of their crystal structures. The molecules are linked together by paired $\mathrm{N}-\mathrm{H} \cdots \mathrm{O}$ hydrogen bonds in $\mathrm{R}_{2}^{2}(8)$ rings, while the $\mathrm{C}-$ $\mathrm{H} \cdots \mathrm{O}$ interactions lead to their further association into double chains. The contribution of the cycloalkyl ring depends on its conformational flexibility and the multiple $\mathrm{C}-\mathrm{H}$ donor implications. In the case of compounds 1-4 bearing the cyclopentyl or the cyclohexyl ring, halogen bonding $(X \cdots O)$ interactions give rise to a supramolecular pseudo-hexagonal network. In addition, the $\mathrm{C}-\mathrm{H} \cdots \mathrm{X}$ interactions with a higher degree of multifurcation at the halogen acceptor have an important role in the formation of the crystal structure. Regarding compounds 5 and 6 with the cycloheptane ring, the $X \cdots O$ interaction is absent, and along with the $\mathrm{C}-\mathrm{H} \cdots \mathrm{X}$ interactions, these compounds realize an alternative crystal structure with an emphasis on the $X \cdots \pi$ interactions. The lattice energies of all these crystal structures, as well as the intermolecular pair energies, have been calculated using PIXEL and further partitioned into coulombic, dispersive, polarization and repulsive factors. The crystal structures have also been subjected to Hirshfeld surface analysis which reveals that approximately $75 \%$ of the close contacts correspond to relatively weak interactions. The application of both concepts has provided a new insight into the relationship between the molecular interactions and crystal structures of the hydantoin derivatives.
\end{abstract}

Received 20th October 2016, Accepted 29th November 2016

DOI: $10.1039 / c 6 c e 02210 c$

www.rsc.org/crystengcomm bonds, substituents attached to the heterocyclic ring delicately influence the overall molecular arrangement. A detailed analysis of the crystal structures of hydantoin derivatives in the Cambridge Structural Database ${ }^{1}$ has revealed four main types of hydrogen bond motifs: $\mathrm{R}_{2}^{2}(8)-1 \mathrm{O}$-tape, $\mathrm{R}_{2}^{2}(8)-2 \mathrm{O}$-tape, $\mathbf{R}_{3}^{3}(12)$-2O-tape and $R_{2}^{2}(8)$-dimer in a network. ${ }^{2}$ Achiral<smiles>[Y]c1ccc(CN2C(=O)NC3(CCC3)C2=O)cc1</smiles>

\begin{tabular}{ccc}
\hline Compound & $\mathrm{n}$ & $\mathrm{X}$ \\
\hline $\mathbf{1}$ & 2 & $\mathrm{Cl}$ \\
$\mathbf{2}$ & 2 & $\mathrm{Br}$ \\
$\mathbf{3}$ & 3 & $\mathrm{Cl}$ \\
$\mathbf{4}$ & 3 & $\mathrm{Br}$ \\
$\mathbf{5}$ & 4 & $\mathrm{Cl}$ \\
$\mathbf{6}$ & 4 & $\mathrm{Br}$ \\
\hline
\end{tabular}

Fig. 1 Molecular structure of the investigated compounds. 

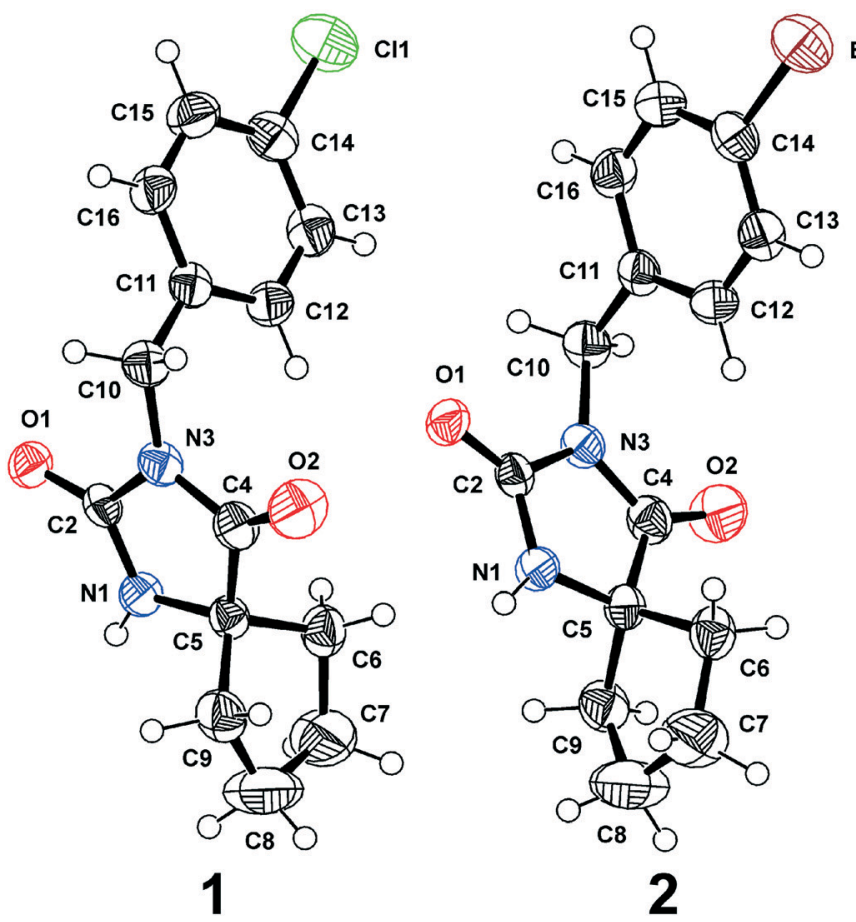
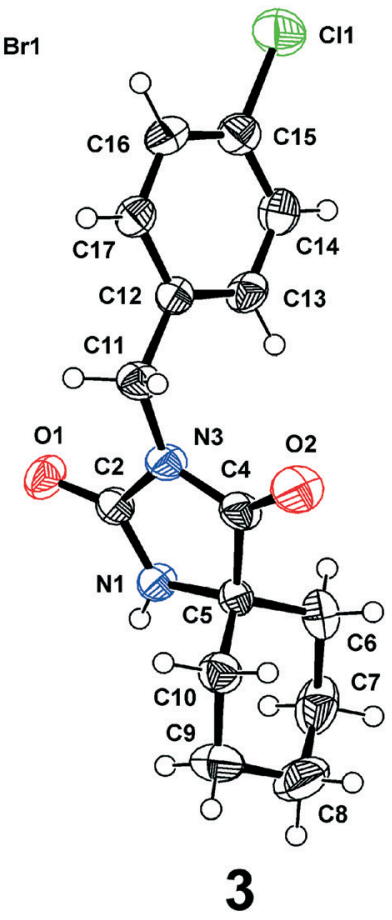

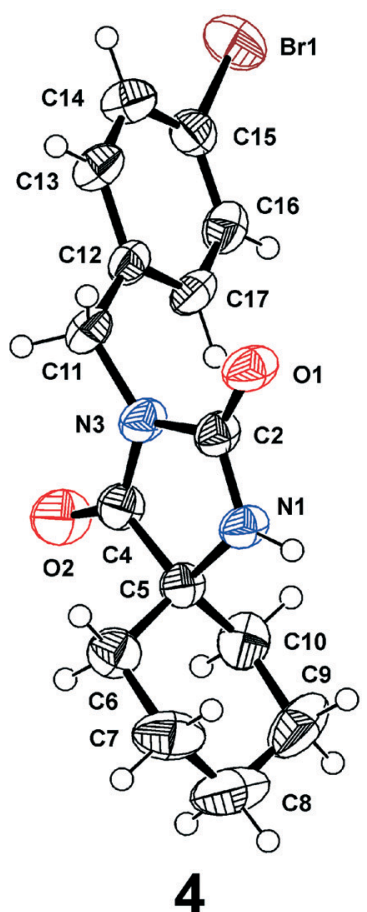

4

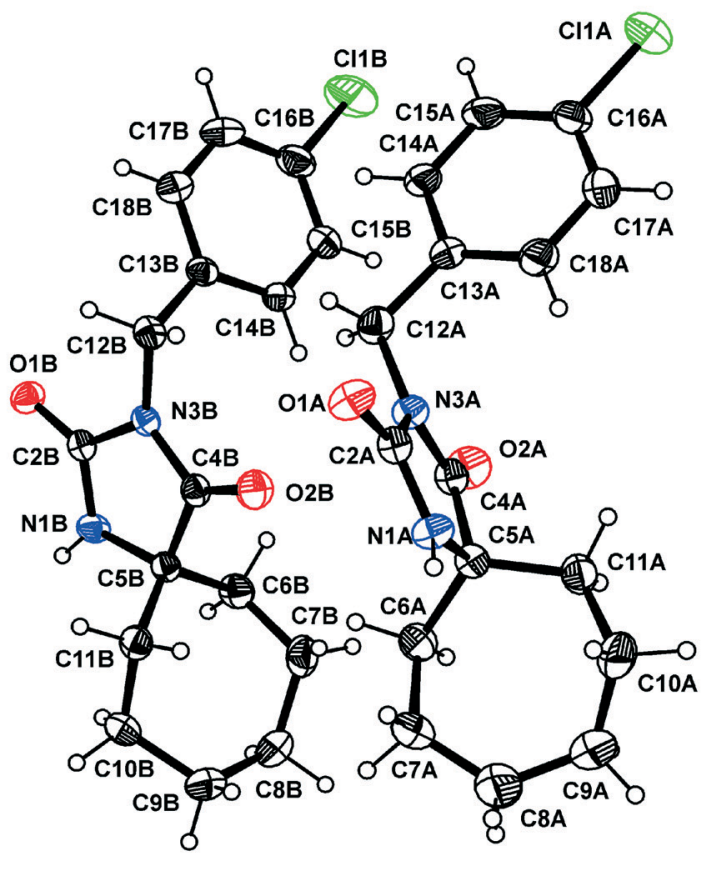

5

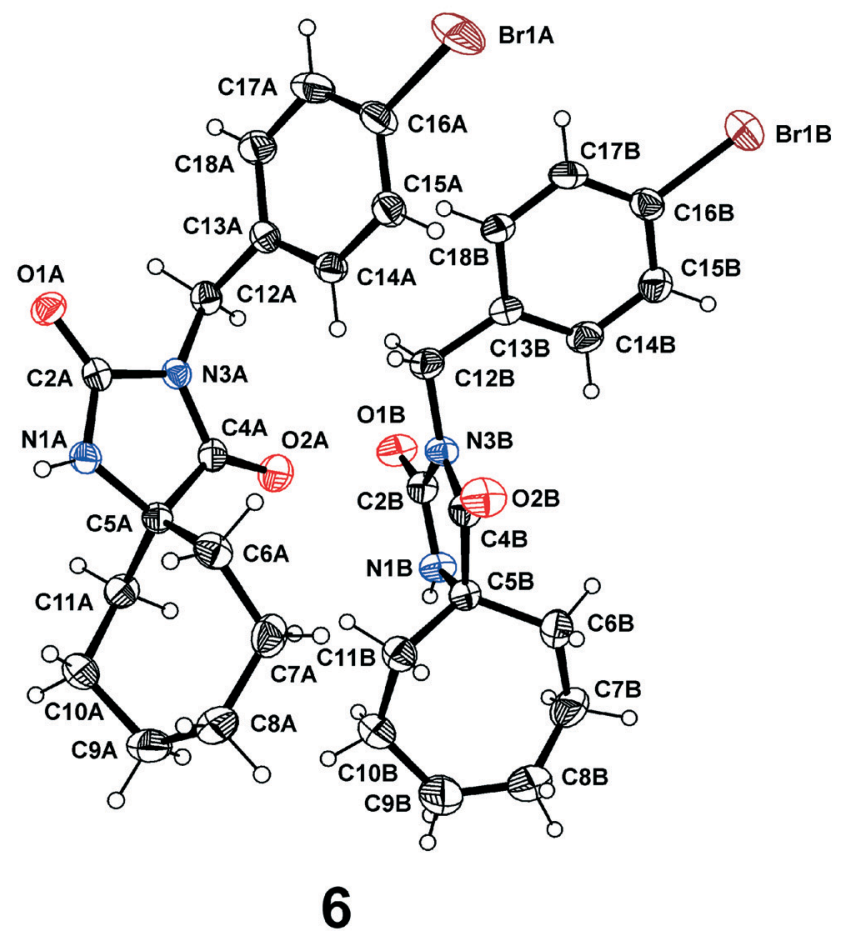

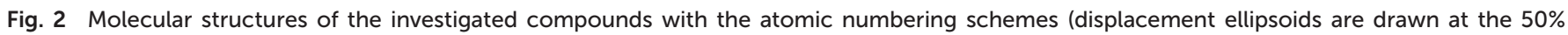

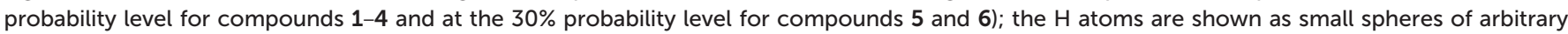
radii.

hydantoin derivatives crystallize with the $\mathrm{R}_{2}^{2}(8)$-2O-tape motifs through inversion symmetry, while chiral compounds usually crystallize with either the $\mathrm{R}_{2}^{2}(8)$-1O-tape or the $\mathrm{R}_{3}^{3}(12)$-2O-tape motifs which are generated through screw axis symmetry. ${ }^{2}$

Hydantoin derivatives are important anticonvulsant drugs; they are employed for the treatment of neurological disorders such as epilepsy and trigeminal neuralgia. Phenytoin (5,5- diphenylhydantoin) is the most important among them, considering its therapeutic significance and its relevance pertaining to the research of anticonvulsant mechanisms. ${ }^{3}$ Mephenytoin (3-methyl-5-ethyl-5-phenylhydantoin) has a spectrum of activity similar to phenytoin, while this drug may exert serious toxic effects. ${ }^{4}$ Due to the low efficacy and pharmacokinetic limitations, ethotoin (3-ethyl-5-phenylhydantoin) is 
Table 1 Selected bond lengths $(\AA)$ and angles $\left(^{\circ}\right)$ of the investigated compounds

\begin{tabular}{|c|c|c|c|c|c|c|c|c|}
\hline & \multirow[b]{2}{*}{1} & \multirow[b]{2}{*}{2} & \multirow[b]{2}{*}{3} & \multirow[b]{2}{*}{4} & \multicolumn{2}{|l|}{5} & \multicolumn{2}{|l|}{6} \\
\hline & & & & & $\mathbf{A}$ & B & $\mathbf{A}$ & B \\
\hline $\mathrm{N} 1-\mathrm{C} 2$ & $1.333(3)$ & $1.336(4)$ & $1.334(2)$ & $1.334(5)$ & $1.330(3)$ & $1.336(3)$ & $1.335(4)$ & $1.335(4)$ \\
\hline N1-C5 & $1.455(3)$ & $1.456(3)$ & $1.459(2)$ & $1.469(5)$ & $1.453(3)$ & $1.458(3)$ & $1.464(5)$ & $1.458(4)$ \\
\hline $\mathrm{O} 1-\mathrm{C} 2$ & $1.219(3)$ & $1.217(3)$ & $1.220(2)$ & $1.224(5)$ & $1.224(3)$ & $1.222(3)$ & $1.222(4)$ & $1.218(4)$ \\
\hline $\mathrm{C} 2-\mathrm{N} 3$ & $1.397(3)$ & $1.401(4)$ & $1.401(2)$ & $1.403(5)$ & $1.396(3)$ & $1.392(3)$ & $1.395(4)$ & $1.392(4)$ \\
\hline $\mathrm{N} 3-\mathrm{C} 4$ & $1.372(3)$ & $1.370(4)$ & $1.372(2)$ & $1.375(5)$ & $1.367(3)$ & $1.365(3)$ & $1.366(4)$ & $1.373(4)$ \\
\hline $\mathrm{O} 2-\mathrm{C} 4$ & $1.200(3)$ & $1.210(4)$ & $1.206(2)$ & $1.214(5)$ & $1.207(3)$ & $1.207(3)$ & $1.205(4)$ & $1.203(4)$ \\
\hline C4-C5 & $1.515(3)$ & $1.516(4)$ & $1.511(2)$ & $1.512(5)$ & $1.523(3)$ & $1.523(3)$ & $1.523(4)$ & $1.527(5)$ \\
\hline $\mathrm{C}_{m+5}-\mathrm{C}_{m+6}$ & $1.508(3)$ & $1.510(4)$ & $1.509(2)$ & $1.512(5)$ & $1.508(3)$ & $1.507(3)$ & $1.511(4)$ & $1.504(4)$ \\
\hline $\mathrm{N} 3-\mathrm{C}_{m+5}$ & $1.448(3)$ & $1.455(4)$ & $1.453(2)$ & $1.447(5)$ & $1.450(3)$ & $1.457(3)$ & $1.455(4)$ & $1.448(5)$ \\
\hline C2-N1-C5 & $113.2(2)$ & $113.3(2)$ & $113.1(2)$ & $112.8(3)$ & $113.6(2)$ & $113.2(2)$ & $113.1(3)$ & $113.4(3)$ \\
\hline $\mathrm{O} 1-\mathrm{C} 2-\mathrm{N} 1$ & $128.9(2)$ & $129.0(3)$ & $128.6(2)$ & $128.4(4)$ & $128.8(2)$ & $128.6(2)$ & $128.4(3)$ & $128.7(3)$ \\
\hline $\mathrm{O} 1-\mathrm{C} 2-\mathrm{N} 3$ & $123.9(2)$ & $124.0(2)$ & $124.0(2)$ & $123.7(3)$ & $123.8(2)$ & $124.1(2)$ & $123.9(3)$ & $123.7(3)$ \\
\hline $\mathrm{N} 1-\mathrm{C} 2-\mathrm{N} 3$ & $107.7(2)$ & $107.0(2)$ & $107.4(1)$ & $107.8(3)$ & $107.4(2)$ & $107.4(2)$ & $107.6(2)$ & $107.6(3)$ \\
\hline $\mathrm{C} 2-\mathrm{N} 3-\mathrm{C} 4$ & $111.5(2)$ & $111.5(2)$ & $110.9(1)$ & $110.5(3)$ & $111.2(2)$ & $111.4(2)$ & $111.2(2)$ & $111.2(2)$ \\
\hline $\mathrm{O} 2-\mathrm{C} 4-\mathrm{N} 3$ & $125.9(3)$ & $125.3(3)$ & $125.6(2)$ & $125.9(3)$ & $125.5(2)$ & $125.7(2)$ & $125.4(3)$ & $125.8(3)$ \\
\hline $\mathrm{O} 2-\mathrm{C} 4-\mathrm{C} 5$ & $127.2(2)$ & $127.6(3)$ & $126.9(3)$ & $126.2(4)$ & $127.2(2)$ & $127.1(2)$ & $127.1(3)$ & $127.1(3)$ \\
\hline N3-C4-C5 & $106.8(2)$ & $107.1(2)$ & $107.6(1)$ & $107.9(3)$ & $107.3(2)$ & $107.2(2)$ & $107.5(3)$ & $107.2(3)$ \\
\hline N1-C5-C4 & $101.2(2)$ & $101.0(2)$ & $100.8(1)$ & $100.6(3)$ & $100.5(2)$ & $100.5(2)$ & $100.4(2)$ & $100.4(2)$ \\
\hline $\mathrm{C}_{m+6}-\mathrm{C}_{m+5}-\mathrm{N} 3$ & $113.7(2)$ & $113.0(2)$ & $115.5(2)$ & $115.4(3)$ & $115.2(2)$ & $113.1(2)$ & $112.9(3)$ & $115.1(3)$ \\
\hline
\end{tabular}

Table 2 Dihedral angle $\left({ }^{\circ}\right)$ between the mean planes defined by the ring units in the investigated compounds

\begin{tabular}{|c|c|c|c|c|}
\hline Compound & & cycAlk-Hyd & Hyd-Ph & cycAlk-Ph \\
\hline 1 & & $89.9(1)$ & $88.4(1)$ & $9.45(1)$ \\
\hline 2 & & $89.8(1)$ & $88.8(1)$ & 14.4(1) \\
\hline 3 & & $88.9(1)$ & $77.4(1)$ & $12.0(1)$ \\
\hline 4 & & 88.1(1) & $80.4(1)$ & $11.8(1)$ \\
\hline \multirow[t]{2}{*}{5} & $\mathbf{A}$ & $86.8(1)$ & $81.8(1)$ & $13.8(1)$ \\
\hline & B & $75.3(1)$ & $76.3(1)$ & $6.23(1)$ \\
\hline \multirow[t]{2}{*}{6} & $\mathbf{A}$ & $75.4(1)$ & $76.4(1)$ & $5.48(1)$ \\
\hline & B & $87.3(1)$ & $81.3(1)$ & $13.0(1)$ \\
\hline
\end{tabular}

Hyd - plane of the hydantoin ring; cycAlk - plane of the cycloalkyl ring; Ph - plane of the phenyl ring.

mostly used as an adjunctive drug in the treatment of generalized tonic-clonic seizures. ${ }^{5}$ In addition to anticonvulsant activity, a variety of other biological activities for hydantoin derivatives have been reported including their application as antiarrhythmic drugs, ${ }^{6}$ bactericides $^{7}$ and drugs in cancer therapy. ${ }^{8}$

In the pharmaceutical industry, crystal packing studies of biologically active compounds are crucial for bioavailability and processing problems. The significance of crystal packing studies of hydantoin derivatives is further enhanced when one recognizes that certain analogies might be drawn between interactions in the crystal packing and interactions with biological matrices. ${ }^{9}$ Anticonvulsant activity of hydantoins is mediated by their interaction and inhibition of the voltage-gated sodium channels in the brain. Regarding the molecular mode of action of phenytoin, the tendency of its amide groups to form hydrogen bonds is transformed into interactions with the aromatic ring of the amino acid residue Phe-1764 to form an amino-aromatic hydrogen bond in the inner pore of the voltage-gated sodium channel. ${ }^{10}$

The exploration of supramolecular structures of hydantoin derivatives has been associated with the study of hydrogen bonding interactions. On the other hand, the formation of different crystal polymorphs also allows the establishment of weak interactions which, when numerous, affect each other. ${ }^{11}$ In this context, a series of cycloalkane-5-spirohydantoins bearing a substituted benzyl group in position 3 of the heterocyclic ring have been synthesized here (Fig. 1) and the evolution of their crystal structures has been analyzed. The conformational flexibility within the investigated series of compounds has been altered by increasing the size of the cycloalkyl ring from cyclopentyl to cycloheptyl. We have introduced a halogen substituent ( $\mathrm{X}=\mathrm{Cl}$ and $\mathrm{Br}$ ) in the benzyl moiety to explore whether their interactions can promote the 
Table 3 PIXEL interaction energies (I.E., $\mathrm{kJ} \mathrm{mol}^{-1}$ ) in the extracted molecular segments related by a symmetry operation and the corresponding intermolecular interactions

\begin{tabular}{|c|c|c|c|c|c|c|c|c|}
\hline & Distance $^{a}, \AA$ & $E_{\text {coul }}$ & $E_{\text {pol }}$ & $E_{\text {disp }}$ & $E_{\text {rep }}$ & $E_{\text {tot }}$ & Symmetry & Important interactions \\
\hline \multicolumn{9}{|c|}{ Compound 1} \\
\hline I & 7.567 & -89.9 & -34.9 & -26.5 & 75.9 & -75.5 & $-x+1,-y+1,-z+1$ & $\mathrm{~N} 1-\mathrm{H} 1 \cdots \mathrm{O} 1$ \\
\hline II & 5.875 & -10.2 & -5.8 & -36.1 & 18.6 & -33.5 & $x, y-1, z$ & $\begin{array}{l}\mathrm{C} 6-\mathrm{H} 6 \mathrm{~A} \cdots \mathrm{O} 1 \\
\mathrm{C} 12-\mathrm{H} 12 \cdots \mathrm{O} 1 \\
\mathrm{C} 13-\mathrm{H} 13 \cdots \mathrm{O} 1\end{array}$ \\
\hline III & 6.305 & -3.7 & -5.8 & -39.3 & 19.9 & -28.9 & $-x+1,-y+1,-z+1$ & $\mathrm{C} 6-\mathrm{H} 6 \mathrm{~A} \cdots \mathrm{N} 1$ \\
\hline IV & 6.581 & -6.9 & -4.5 & -28.4 & 17.5 & -22.3 & $-x+1 / 2, y+1 / 2,-z+3 / 2$ & $\begin{array}{l}\mathrm{C} 15-\mathrm{H} 15 \cdots \mathrm{O} 2 \\
\mathrm{C} 16-\mathrm{H} 16 \cdots \mathrm{O} 2 \\
\mathrm{C} 10-\mathrm{H} 10 \mathrm{~B} \cdots \pi\end{array}$ \\
\hline $\mathrm{V}$ & 9.997 & -6.0 & -1.3 & -13.4 & 6.0 & -14.7 & $x-1 / 2,-y+1 / 2, z-1 / 2$ & C9-H9B $\cdots \mathrm{Cl} 1$ \\
\hline VI & 10.815 & -4.3 & -2.4 & -14.0 & 8.6 & -12.1 & $x-1 / 2,-y-1 / 2, z-1 / 2$ & $\begin{array}{l}\text { C6-H6B } \cdots \text { Cl1 } \\
\text { C9-H9A } \cdots \text { Cl1 } \\
\text { Cl1 } \cdots \text { O } 2\end{array}$ \\
\hline $\begin{array}{l}\text { VII } \\
\text { Con }\end{array}$ & $\begin{array}{l}12.667 \\
\text { ad } 2\end{array}$ & -6.0 & -3.0 & -13.6 & 10.4 & -12.1 & $-x+1,-y,-z+2$ & $\mathrm{C} 15-\mathrm{H} 15 \cdots \mathrm{Cl} 1$ \\
\hline I & 8.484 & -85.5 & -30.9 & -26.2 & 72.3 & -70.3 & $-x+1,-y,-z+1$ & $\mathrm{~N} 1-\mathrm{H} 1 \cdots \mathrm{O} 1$ \\
\hline II & 5.926 & -9.8 & -5.5 & -35.6 & 18.1 & -32.8 & $x, y+1, z$ & $\begin{array}{l}\mathrm{C} 6-\mathrm{H} 6 \mathrm{~B} \cdots \mathrm{O} 1 \\
\mathrm{C} 12-\mathrm{H} 12 \cdots \mathrm{O} 1 \\
\mathrm{C} 13-\mathrm{H} 13 \cdots \mathrm{O} 1\end{array}$ \\
\hline III & 6.906 & -5.2 & -6.3 & -40.9 & 21.7 & -30.5 & $-x+1,-y+1,-z+1$ & $\mathrm{C} 6-\mathrm{H} 6 \mathrm{~B} \cdots \mathrm{N} 1$ \\
\hline IV & 6.251 & -5.4 & -4.1 & -27.3 & 15.7 & -21.1 & $-x+1 / 2, y-1 / 2,-z+3 / 2$ & $\begin{array}{l}\mathrm{C} 16-\mathrm{H} 16 \cdots \mathrm{O} 2 \\
\mathrm{C} 10-\mathrm{H} 10 \mathrm{~B} \cdots \pi\end{array}$ \\
\hline $\mathrm{V}$ & 10.174 & -5.6 & -1.0 & -12.2 & 4.7 & -14.2 & $x-1 / 2,-y+1 / 2, z-1 / 2$ & C9-H9A $\cdots$ Br1 \\
\hline VI & 10.693 & -8.0 & -2.8 & -14.2 & 12.4 & -12.5 & $x-1 / 2,-y+3 / 2, z-1 / 2$ & $\begin{array}{l}\text { C6-H6A } \cdots \mathrm{Br} 1 \\
\text { C9-H9B } \cdots \mathrm{Br} 1 \\
\mathrm{Br} 1 \cdots \mathrm{O} 2\end{array}$ \\
\hline $\begin{array}{l}\text { VII } \\
\text { Con }\end{array}$ & $\begin{array}{l}11.358 \\
\text { ad } 3\end{array}$ & -5.8 & -2.3 & -13.7 & 11.3 & -10.4 & $-x+1,-y+1,-z+2$ & $\mathrm{C} 15-\mathrm{H} 15 \cdots \mathrm{Br} 1$ \\
\hline I & 7.779 & -81.1 & -29.0 & -28.5 & 65.3 & -73.3 & $-x+1,-y+1,-z+1$ & $\begin{array}{l}\mathrm{N} 1-\mathrm{H} 1 \cdots \mathrm{O} 1 \\
\mathrm{C} 7-\mathrm{H} 7 \mathrm{~A} \cdots \mathrm{O} 1 \\
\mathrm{C} 7-\mathrm{H} 7 \mathrm{~B} \cdots \mathrm{O} 1\end{array}$ \\
\hline II & 5.913 & -9.7 & -5.5 & -36.2 & 17.1 & -34.4 & $x, y-1, z$ & $\begin{array}{l}\mathrm{C} 13-\mathrm{H} 13 \cdots \mathrm{O} 1 \\
\mathrm{C} 6-\mathrm{H} 6 \mathrm{~B} \cdots \mathrm{O} 1\end{array}$ \\
\hline III & 6.350 & -5.8 & -5.3 & -39.2 & 19.6 & -30.7 & $-x+1,-y,-z+1$ & $\begin{array}{l}\mathrm{C} 6-\mathrm{H} 6 \mathrm{~B} \cdots \mathrm{N} 1 \\
\mathrm{C} 7-\mathrm{H} 7 \mathrm{~B} \cdots \mathrm{O} 1\end{array}$ \\
\hline IV & 6.689 & -10.1 & -6.0 & -30.7 & 22.9 & -23.8 & $-x+1 / 2, y+1 / 2,-z+3 / 2$ & $\begin{array}{l}\mathrm{C} 11-\mathrm{H} 11 \cdots \pi \\
\mathrm{C} 17-\mathrm{H} 17 \cdots \mathrm{O} 2 \\
\mathrm{C} 16-\mathrm{H} 16 \cdots \mathrm{O} 2\end{array}$ \\
\hline $\mathrm{V}$ & 10.653 & -5.9 & -1.6 & -15.7 & 8.1 & -15.1 & $x-1 / 2,-y+1 / 2, z-1 / 2$ & $\mathrm{C} 10-\mathrm{H} 10 \mathrm{~B} \cdots \mathrm{Cl} 1$ \\
\hline VI & 11.325 & -4.7 & -2.8 & -15.7 & 9.6 & -13.5 & $x-1 / 2,-y-1 / 2, z-1 / 2$ & $\begin{array}{l}\text { C6-H6A } \cdots \text { Cl1 } \\
\text { C10-H10A } \cdots \text { Cl1 } \\
\text { Cl1 } \cdots \mathrm{O} 2\end{array}$ \\
\hline \multicolumn{8}{|c|}{ Compound 4} & $\mathrm{C} 16-\mathrm{H} 16 \cdots \mathrm{Cl} 1$ \\
\hline I & 8.843 & -82.5 & -30.1 & -28.3 & 64.3 & -76.6 & $-x+1,-y,-z+1$ & $\begin{array}{l}\mathrm{N} 1-\mathrm{H} 1 \cdots \mathrm{O} 1 \\
\mathrm{C} 7-\mathrm{H} 7 \mathrm{~B} \cdots \mathrm{O} 1 \\
\mathrm{C} 9-\mathrm{H} 9 \mathrm{~B} \cdots \mathrm{O} 1\end{array}$ \\
\hline II & 5.934 & -9.8 & -5.1 & -35.6 & 16.8 & -33.7 & $x, y+1, z$ & $\mathrm{C} 17-\mathrm{H} 17 \cdots \mathrm{O} 1$ \\
\hline III & 7.126 & -5.7 & -4.9 & -39.2 & 19.7 & -30.2 & $-x+1,-y+1,-z+1$ & $\begin{array}{l}\mathrm{C} 10-\mathrm{H} 10 \mathrm{~A} \cdots \mathrm{N} 1 \\
\mathrm{C} 9-\mathrm{H} 9 \mathrm{~A} \cdots \mathrm{O} 1\end{array}$ \\
\hline IV & 6.104 & -9.3 & -5.5 & -30.3 & 21.7 & -23.4 & $-x+3 / 2, y-1 / 2,-z+1 / 2$ & $\begin{array}{l}\mathrm{C} 11-\mathrm{H} 11 \mathrm{~B} \cdots \pi \\
\mathrm{C} 13-\mathrm{H} 13 \cdots \mathrm{O} 2 \\
\mathrm{C} 14-\mathrm{H} 14 \cdots \mathrm{O} 2\end{array}$ \\
\hline V & 10.997 & -5.2 & -1.2 & -13.3 & 6.5 & -13.2 & $x+1 / 2,-y+1 / 2, z+1 / 2$ & $\mathrm{C} 6-\mathrm{H} 6 \mathrm{~A} \cdots \mathrm{Br} 1$ \\
\hline VI & 11.346 & -5.8 & -2.4 & -14.4 & 10.2 & -12.3 & $x+1 / 2,-y+3 / 2, z+1 / 2$ & $\begin{array}{l}\text { C6-H6B } \cdots \mathrm{Br} 1 \\
\mathrm{C} 10-\mathrm{H} 10 \mathrm{~B} \cdots \mathrm{Br} 1 \\
\mathrm{Br} 1 \cdots \mathrm{O} 2\end{array}$ \\
\hline $\begin{array}{l}\text { VII } \\
\text { Con }\end{array}$ & $\begin{array}{l}12.414 \\
\mathrm{~d} 5(\mathrm{~A} \cdots \mathrm{A})\end{array}$ & -3.4 & -1.4 & -10.3 & 6.4 & -8.7 & $-x+1,-y+1,-z$ & $\mathrm{C} 14-\mathrm{H} 14 \cdots \mathrm{Br} 1$ \\
\hline I & 7.902 & -90.1 & -34.3 & -30.7 & 75.4 & -79.9 & $-x,-y+1,-z+1$ & $\begin{array}{l}\text { N1A-H1A } \cdots \text { O1A } \\
\text { C7A-H7A1 } \cdots \text { O1A } \\
\text { C10A-H10B } \cdots \text { O1 }\end{array}$ \\
\hline II & 6.757 & -5.6 & -4.5 & -35.9 & 15.6 & -30.5 & $-x-1,-y+1,-z+1$ & $\mathrm{C} 10 \mathrm{~A}-\mathrm{H} 10 \mathrm{~A} \cdots \mathrm{O} 1 \mathrm{~A}$ \\
\hline III & 6.434 & -4.6 & -3.1 & -26.5 & 8.9 & -25.3 & $x-1, y, z$ & C11A-H11B $\cdots$ O1 \\
\hline IV & 9.781 & -1.7 & -1.2 & -22.3 & 7.1 & -14.7 & $-x-1,-y+2,-z+1$ & $\operatorname{Cl} 1 \mathrm{~A} \cdots \pi$ \\
\hline $\mathrm{V}$ & 13.594 & -4.0 & -2.7 & -14.8 & 12.3 & -9.4 & $x, y-1, z$ & C9-H9A2 ‥ Cl1A \\
\hline
\end{tabular}


Table 3 (continued)

\begin{tabular}{|c|c|c|c|c|c|c|c|c|}
\hline & Distance $^{a}, \AA$ & $E_{\text {coul }}$ & $E_{\text {pol }}$ & $E_{\text {disp }}$ & $E_{\text {rep }}$ & $E_{\text {tot }}$ & Symmetry & Important interactions \\
\hline \multicolumn{9}{|c|}{$\mathrm{A} \cdots \mathrm{B} / \mathrm{B} \cdots \mathrm{A}$} \\
\hline VII & 5.488 & -12.3 & -7.2 & -42.4 & 28.1 & -33.8 & $x-1, y, z$ & $\begin{array}{l}\text { C11B-H11D } \cdots \text { O2A } \\
\operatorname{lp}(\mathrm{O} 2 \mathrm{~A}) \cdots \pi\end{array}$ \\
\hline VIII & 5.616 & -12.4 & -6.9 & -42.0 & 27.7 & -33.5 & $x, y, z$ & $\begin{array}{l}\text { C12-H12B } \cdots \text { O2B } \\
\text { C6A-H6A1 } \cdots \text { O2B } \\
\operatorname{lp}(\mathrm{O} 2 \mathrm{~B}) \cdots \pi\end{array}$ \\
\hline $\mathrm{x}$ & 7.574 & -77.0 & -24.8 & -22.0 & 60.8 & -63.0 & $-x+1,-y+1,-z+2$ & N1B-H1B $\cdots$ O1B \\
\hline $\mathrm{XI}$ & 4.707 & -15.7 & -8.5 & -69.6 & 37.4 & -56.4 & $-x,-y+1,-z+2$ & $\begin{array}{l}\text { C7B-H7B2 } \cdots \text { O1B } \\
\text { C6B-H6B2 } \cdots \text { N1B } \\
\text { C8-H8B1 } \cdots \pi\end{array}$ \\
\hline XII & 6.434 & -12.7 & -7.3 & -37.3 & 25.7 & -31.6 & $x-1, y, z$ & $\begin{array}{l}\text { C15B-H15B } \cdots \text { O1B } \\
\text { C14B-H14B } \cdots \text { O1B } \\
\text { C7B-H7B2 } \cdots \text { N1B }\end{array}$ \\
\hline III & 6.458 & -13.2 & -7.3 & -37.3 & 25.3 & -32.5 & $x+1, y, z$ & $\begin{array}{l}\text { C14A-H12 } \cdots \text { O1A } \\
\text { C15A-H13 } \cdots \text { O1A } \\
\text { C7A-H2A } \cdots \text { N1A }\end{array}$ \\
\hline \multicolumn{9}{|c|}{$\mathrm{A} \cdots \mathrm{B} / \mathrm{B} \cdots \mathrm{A}$} \\
\hline IV & 5.670 & -13.4 & -7.1 & -43.5 & 29.0 & -34.9 & $x, y, z$ & $\begin{array}{l}\text { C18B-H32 } \cdots \pi \\
\text { C12B-H26A } \cdots \text { O2A } \\
\text { C11B-H22B } \cdots \text { O2A } \\
\operatorname{lp}(\mathrm{O} 2 \mathrm{~A}) \cdots \pi\end{array}$ \\
\hline $\mathrm{V}$ & 5.576 & -12.6 & -7.0 & -42.8 & 28.7 & -33.7 & $x-1, y, z$ & $\begin{array}{l}\text { C11A-H6A } \cdots \text { O2B } \\
\operatorname{lp}(\mathrm{O} 2 \mathrm{~B}) \cdots \pi\end{array}$ \\
\hline $\begin{array}{l}\text { VI } \\
\mathrm{B} \cdots \mathrm{B}\end{array}$ & 13.612 & -3.1 & -1.3 & -12.2 & 5.9 & -10.7 & $x, y-1, z$ & C9B-H20A $\cdots$ Br1A \\
\hline
\end{tabular}

formation of different structural motifs. The planarity of this aromatic system may facilitate intermolecular interactions of the halogen atoms which are less sterically hindered than in an aliphatic system.

When present in organic compounds, halogens can be involved in a variety of intermolecular interactions. A systematic statistical analysis of the Cambridge Structural Database has revealed that, in comparison to analogous $\mathrm{C}-\mathrm{H} \cdots \mathrm{O}$ and $\mathrm{C}-\mathrm{H} \cdots \mathrm{N}$ interactions, the short $\mathrm{C}-\mathrm{H} \cdots \mathrm{X}$ interactions are less frequent or just sporadic depending on the halogen atom. ${ }^{12}$ Formerly considered controversial, these interactions are now regarded as weak hydrogen bonds, where lower coulombic stabilization is compensated by dispersion. ${ }^{13}$ Considering their directionality, the $\mathrm{C}-\mathrm{H} \cdots \mathrm{X}$ interactions are easily distorted from linearity and the bent bonds are entropy favoured. ${ }^{14}$ On the other hand, in $\mathrm{X} \cdots \mathrm{O}$ halogen bonds a Lewis base places a region of charge concentration to a re- gion of positive electrostatic potential on the outer side of a halogen atom ( $\sigma$-hole). ${ }^{12,15}$ Despite the fact that dispersion also plays an important role in this interaction, the directionality of the halogen bond results from the coulombic interaction between the $\sigma$-hole of a halogen atom and a Lewis base. $^{16}$

When hydrogen bonding and halogen bonding exist simultaneously, the hydrogen atom in hydrogen bonding and the halogen atom in halogen bonding compete with each other as an electron acceptor. ${ }^{17}$ The nature and the number of these interactions make prediction of the crystal structure very difficult. To explain the supramolecular preferences of the investigated compounds, we have put emphasis on features which distinguish the halogen bonding from hydrogen bonding, including higher directionality, size of the interacting atom and the possibility to modify the strength of interactions by changing the 


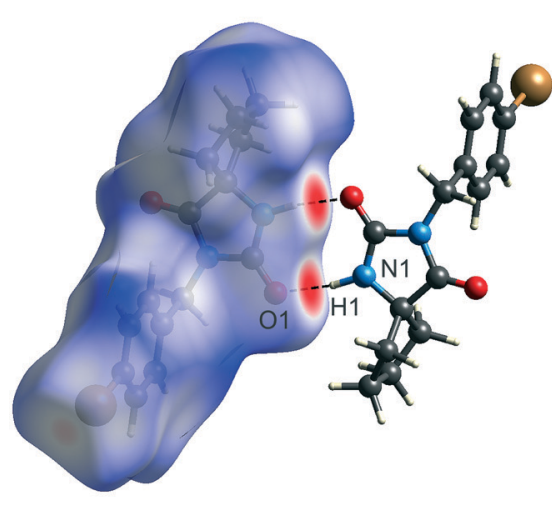

I, $-70.3 \mathrm{~kJ} \mathrm{~mol}^{-1}$

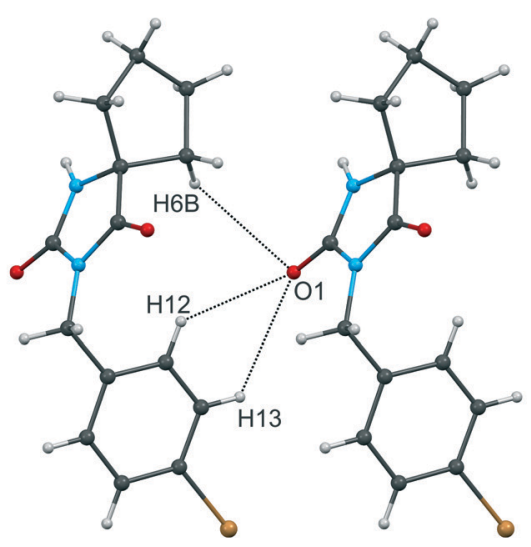

II, $-32.8 \mathrm{~kJ} \mathrm{~mol}^{-1}$

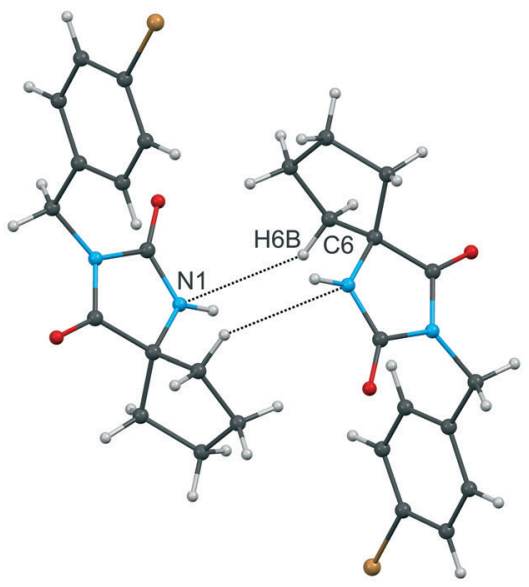

III, $-30.5 \mathrm{~kJ} \mathrm{~mol}^{-1}$
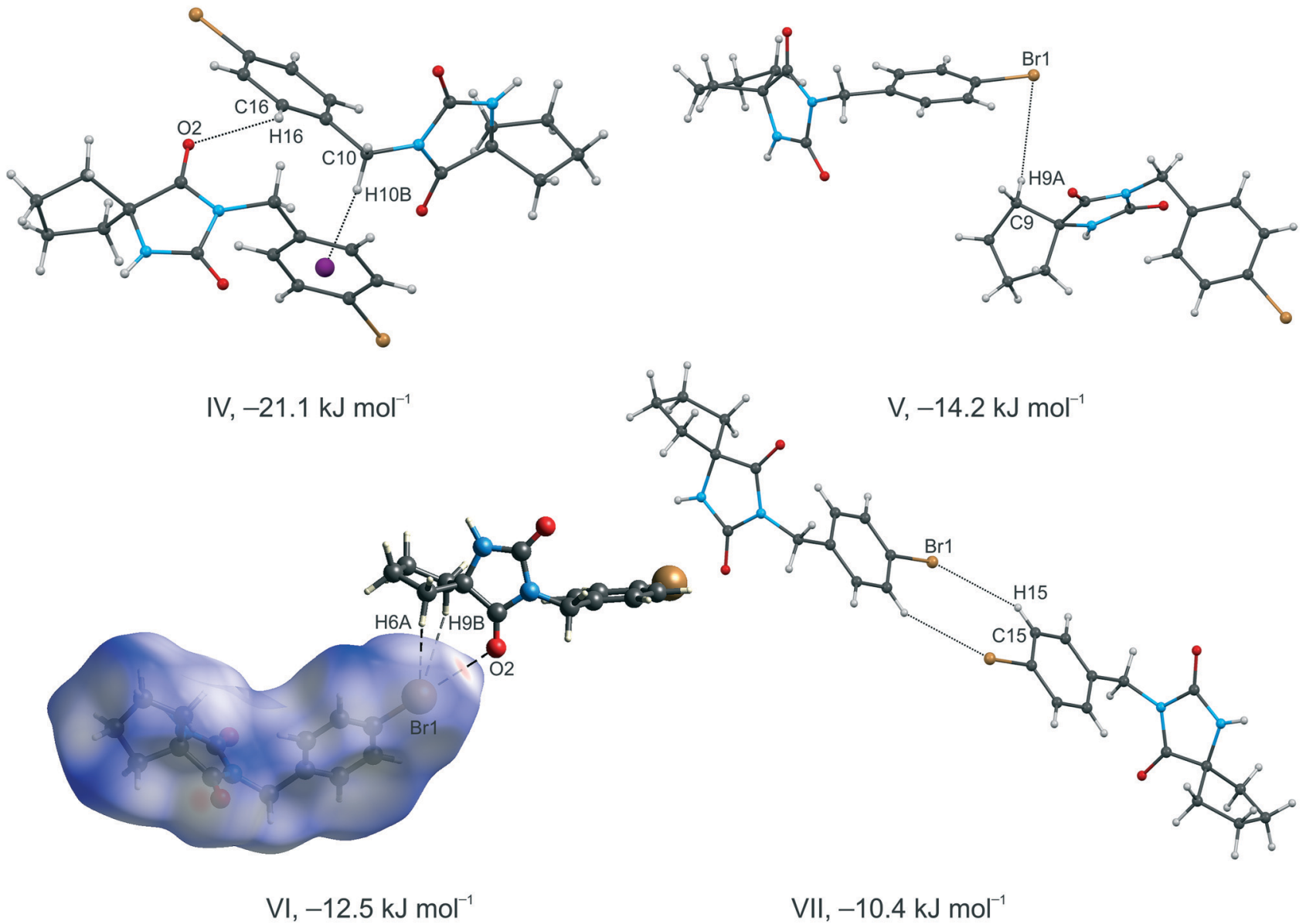

Fig. 3 Molecular segments of 2 with decreasing interaction energy (Table 3), showing the most important intermolecular interactions. The Hirshfeld surface mapped with $d_{\text {norm }}$ is presented in segments I and VI.

halogen substituent. By exploring the molecular geometry of the investigated compounds and quantifying the intermolecular interactions based on the Hirshfeld surface analysis ${ }^{18}$ and the PIXEL method, ${ }^{19}$ the present study will help gain an insight into the relationship between the molecular interactions and crystal structures of hydantoin derivatives.

\section{Results and discussion}

\section{Molecular structures}

The representative ORTEP diagrams of 1-6 are shown in Fig. 2. The cyclopentane ring in compounds 1 and 2 has an envelope conformation, while the cyclohexane ring in compounds 3 and 4 displays a stable chair conformation 
Table 4 Hydrogen bonding geometry $(\AA \AA$, o)

\begin{tabular}{|c|c|c|c|c|c|}
\hline 2 & $\mathrm{~N} 1-\mathrm{H} 1 \cdots \mathrm{O} 1^{\mathrm{ii}}$ & 0.86 & $2.883(3)$ & 2.03 & 172 \\
\hline 4 & $\mathrm{~N} 1-\mathrm{H} 1 \cdots \mathrm{O} 1^{\mathrm{ii}}$ & 0.86 & $2.930(4)$ & 2.07 & 174 \\
\hline \multirow[t]{2}{*}{5} & N1A-H1A $\cdots$ O1A ${ }^{i i i}$ & 0.86 & $2.886(3)$ & 2.03 & 171 \\
\hline & $\mathrm{N} 1 \mathrm{~B}-\mathrm{H} 1 \mathrm{~B} \cdots \mathrm{O} 1 \mathrm{~B}^{\mathrm{iv}}$ & 0.86 & $2.892(3)$ & 2.06 & 163 \\
\hline 6 & $\mathrm{~N} 1 \mathrm{~A}-\mathrm{H} 1 \mathrm{~A} 1 \cdots \mathrm{O} 1 \mathrm{~A}^{\mathrm{v}}$ & 0.86 & $2.892(3)$ & 2.06 & 163 \\
\hline
\end{tabular}

Symmetry codes: (i) $-x+1,-y+1,-z+1$; (ii) $-x+1,-y,-z+1$; (iii) $-x,-y+1,-z+1$; (iv) $-x+1,-y+1,-z+2$; (v) $-x+1,-y,-z$; (vi) $-x+2,-y$, $-z+1$.

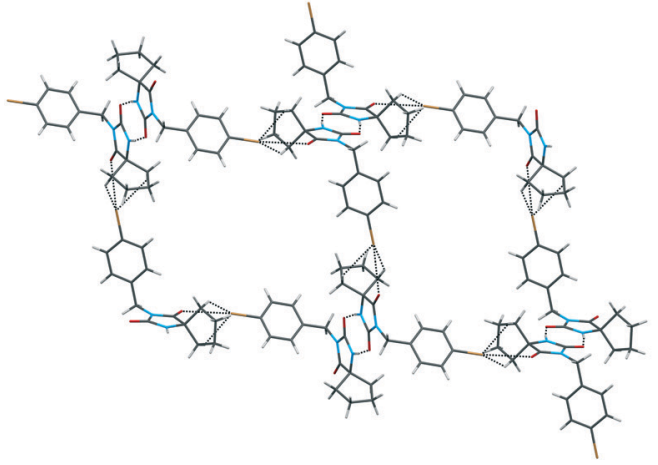

a)

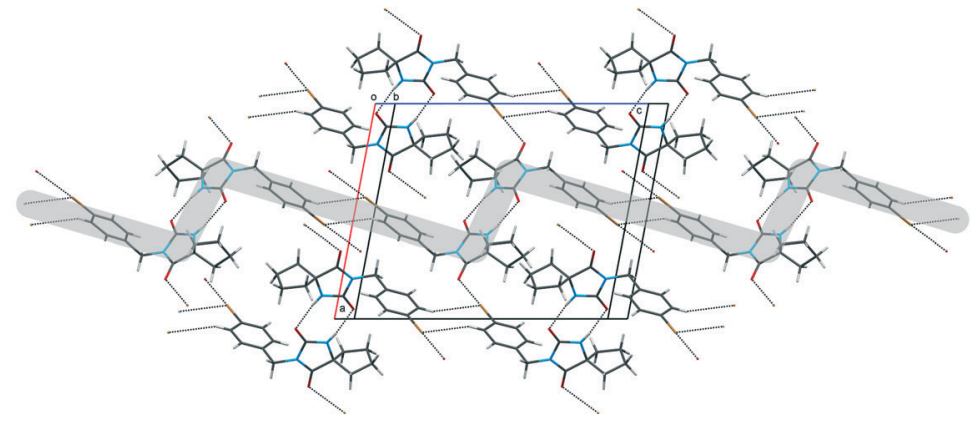

b)

Fig. 4 a) Part of the crystal structure of 2 , showing the linking of the hydrogen-bonded $\mathrm{R}_{2}^{2}(8)$ dimers by $\mathrm{C}-\mathrm{H} \cdots \mathrm{Br}$ and $\mathrm{O} \cdots \mathrm{Br}$ interactions to generate a supramolecular pseudo-hexagonal network; b) part of the crystal structure of 2, showing the formation of a zigzag chain of $\mathrm{R}_{2}^{2}(8)$ rings through $\mathrm{N}-\mathrm{H} \cdots \mathrm{O}$ and $\mathrm{C}-\mathrm{H} \cdots \mathrm{Br}$ hydrogen bonds (projection approximately onto the ac-plane).

(Table S1 $\uparrow$ ). Compounds 5 and $\mathbf{6}$, on the other hand, crystallize with two molecules in the asymmetric unit (molecules A and B, Fig. 2), differentiating primarily in the conformation of the cycloheptane ring. This flexible ring adopts a chair conformation in one of the molecules, while it is distorted in the other one with the twisted-chair conformation (Table $\mathrm{S} 1 \dagger)$. The $\mathrm{N}-\mathrm{H}$ bond of the hydantoin ring almost always occupies an axial position ${ }^{20}$ and the investigated compounds 1-6 are no exception.

The selected molecular geometry parameters of the investigated compounds are presented in Table 1 . The bond lengths and angles of the hydantoin moieties are affected by the $\pi$-conjugation in the amide fragments ${ }^{20}$ while the size of the cycloalkyl ring has little or no effect on them. The $\mathrm{C} 2=\mathrm{O} 1$ bond is slightly longer than the $\mathrm{C} 4=\mathrm{O} 2$ bond and this difference becomes smaller when the bromo substituent

Table 5 Geometric parameters for halogen bonds ( $(\AA, \circ)$

\begin{tabular}{llll}
\hline Compound & $d(\mathrm{C}-\mathrm{X} \cdots \mathrm{O})$ & $\mathrm{C}-\mathrm{X} \cdots \mathrm{O}$ & $\mathrm{X} \cdots \mathrm{O}-\mathrm{C}$ \\
\hline 1 & 3.284 & 174.7 & 122.6 \\
2 & 3.220 & 173.8 & 124.9 \\
3 & 3.673 & 165.0 & 115.9 \\
4 & 3.684 & 165.0 & 117.6
\end{tabular}

is present in the benzyl moiety. The bonds involving the spirocarbon atom, C4-C5 (average 1.52 ̊̊) and N1-C5 (average $1.46 \AA$ ), are the longest in the hydantoin ring as a result of a higher $\sigma$ character. The other $\mathrm{C}-\mathrm{N}$ bonds have a $\pi$ character, while the N1-C2 bond (average 1.32 $\AA$ ) is the shortest among them. The $\mathrm{C}_{m+5}-\mathrm{C}_{m+6}$ (average 1.51 $\mathrm{\AA}$ ) and N3- $\mathrm{C}_{m+5}$ (average $1.45 \AA$ A) bonds connecting the hydantoin and phenyl rings show a $\sigma$ character. It has been demonstrated that the introduction of an electron-withdrawing halogen substituent in the benzyl moiety results in the shortening of the former and the extension of the latter bond when compared to the compound with the unsubstituted benzyl group. ${ }^{21}$ Bending of the $\mathrm{C} 2=\mathrm{O} 1$ bond toward $\mathrm{N} 3$ is a common structural feature of the hydantoin moiety. ${ }^{20}$ The $\mathrm{O} 1-\mathrm{C} 2-\mathrm{N} 1$ angle is greater than the $\mathrm{O} 1-\mathrm{C} 2-\mathrm{N} 3$ angle for $c a .5^{\circ}$, which results from a stronger repulsion between the lone pairs of the carbonyl oxygen $\mathrm{O} 1$ and the electron pairs in the $\mathrm{N} 3-\mathrm{C} 2$ bond. The corresponding angles around $\mathrm{C} 4$ are practically the same (Table 1).

As expected, the hydantoin moiety is almost planar in all cases. With the exception of molecules $5 \mathrm{~B}$ and $6 \mathrm{~A}$, the planes defined by the hydantoin ring and cycloalkane are nearly perpendicular to the corresponding dihedral mean plane angles ranging from $86.8^{\circ}$ in $\mathbf{5 A}$ to $89.9^{\circ}$ in $\mathbf{1}$ (Table 2). The planes 


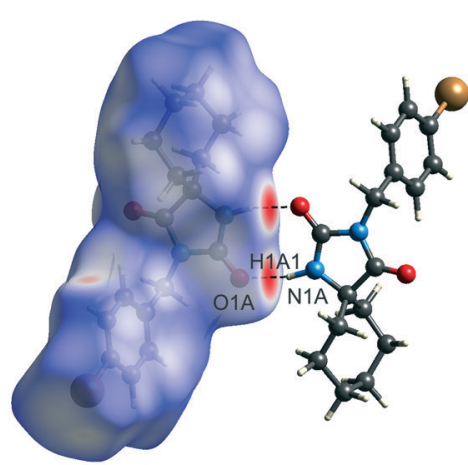

$\mathrm{I},-68.3 \mathrm{~kJ} \mathrm{~mol}^{-1}$

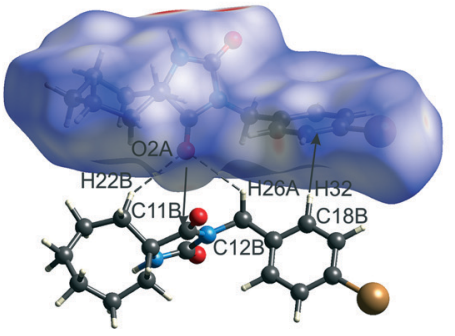

IV, $-34.9 \mathrm{~kJ} \mathrm{~mol}^{-1}$

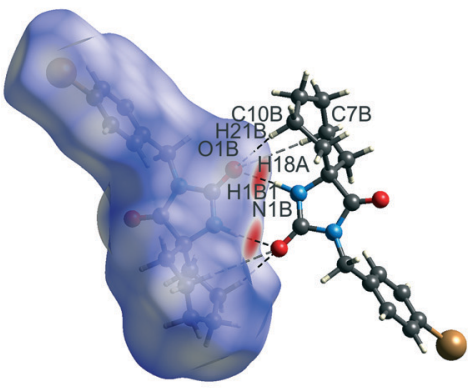

VII, $-76.4 \mathrm{~kJ} \mathrm{~mol}^{-1}$

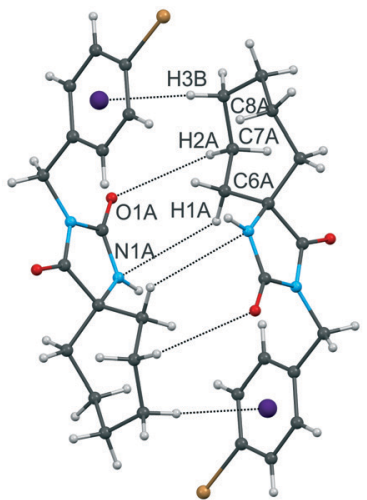

II, $-57.2 \mathrm{~kJ} \mathrm{~mol}^{-1}$

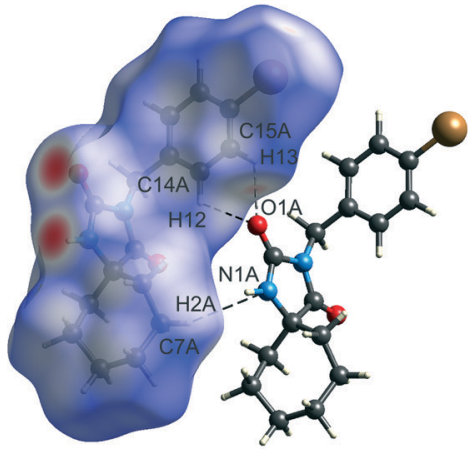

III, $-32.5 \mathrm{~kJ} \mathrm{~mol}^{-1}$

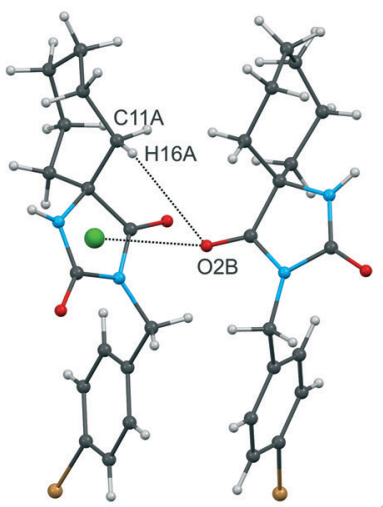

$\mathrm{V},-33.7 \mathrm{~kJ} \mathrm{~mol}^{-1}$

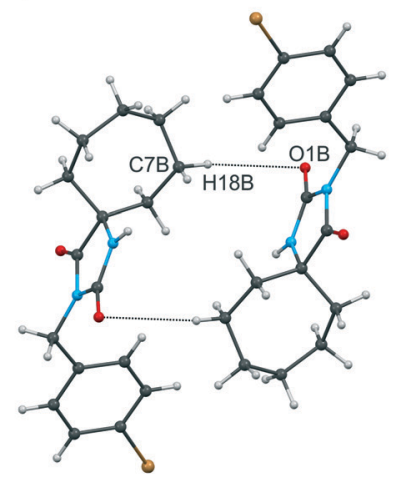

VIII, $-30.1 \mathrm{~kJ} \mathrm{~mol}^{-1}$
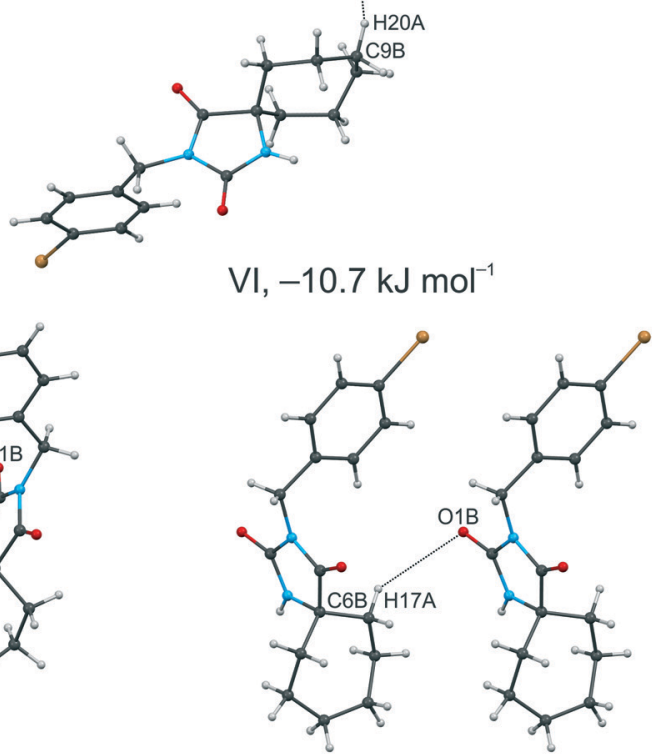

IX, $-24.7 \mathrm{~kJ} \mathrm{~mol}^{-1}$

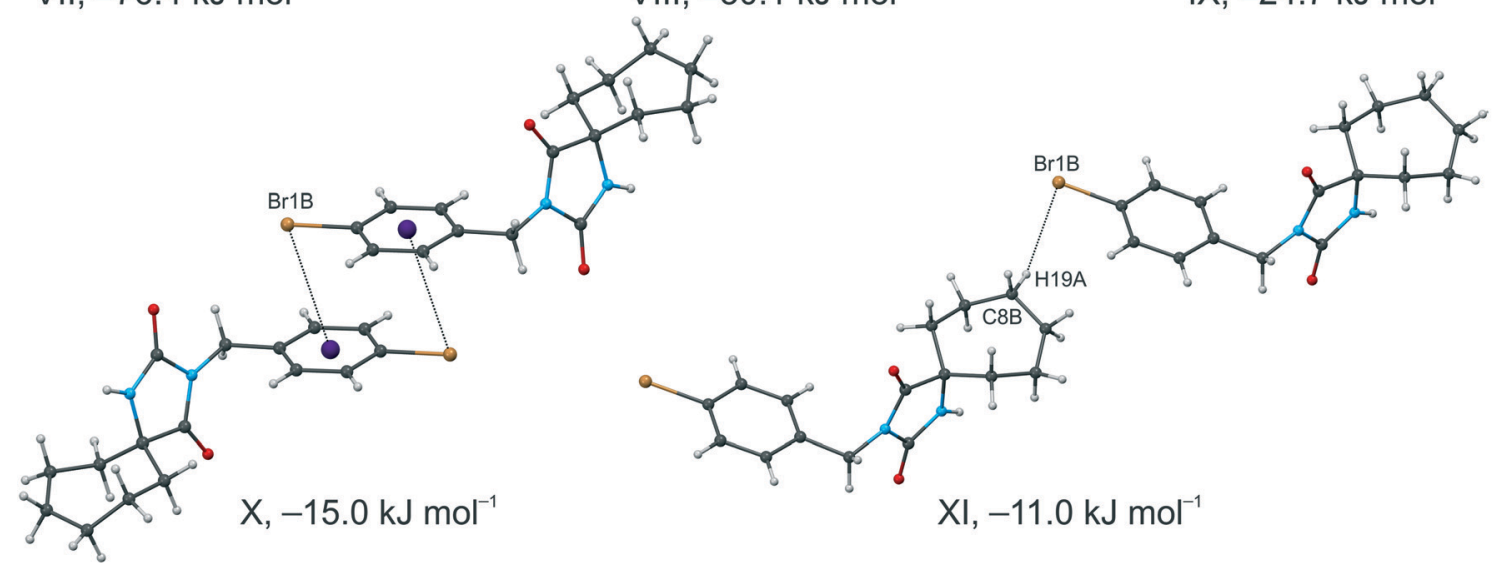

Fig. 5 Molecular segments of 6 with decreasing interaction energy (Table 3), showing the most important intermolecular interactions. The Hirshfeld surface mapped with $d_{\text {norm }}$ is presented in segments I, III, IV and VII. 


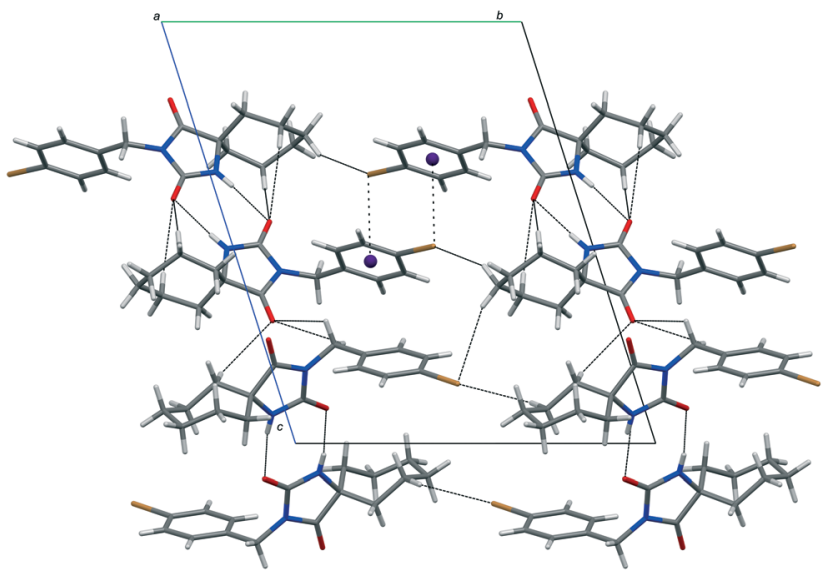

Fig. 6 Part of the crystal structure of 6 , showing the linking of the hydrogen-bonded $\mathrm{R}_{2}^{2}(8)$ homodimers by the $\mathrm{C}-\mathrm{H} \cdots \mathrm{Br}$ and $\mathrm{C}-\mathrm{Br} \cdots \pi$ interactions to form double chains (projection onto the $b c$-plane). For clarity, the cross-linking between the neighboring chains by the $\mathrm{C}$ $\mathrm{H} \cdots \mathrm{Br}$ and $\mathrm{C}-\mathrm{H} \cdots \mathrm{O}$ interactions is only presented.

Table 6 Lattice energies partitioned into coulombic, polarization, dispersion and repulsion contributions using PIXEL $\left(\mathrm{KJ} \mathrm{mol}^{-1}\right)$

\begin{tabular}{llllll}
\hline Compound & $E_{\text {coul }}$ & $E_{\text {pol }}$ & $E_{\text {disp }}$ & $E_{\text {rep }}$ & $E_{\text {tot }}$ \\
\hline $\mathbf{1}$ & -76.8 & -33.0 & -146.5 & 109.6 & -146.6 \\
$\mathbf{2}$ & -76.4 & -30.5 & -144.8 & 109.6 & -142.1 \\
$\mathbf{3}$ & -76.9 & -31.0 & -153.9 & 110.0 & -151.9 \\
$\mathbf{4}$ & -77.1 & -29.4 & -149.1 & 107.7 & -147.9 \\
$\mathbf{5}$ & -74.9 & -31.1 & -155.2 & 110.7 & -150.6 \\
$\mathbf{6}$ & -77.5 & -31.4 & -159.0 & 114.3 & -153.7
\end{tabular}

of the hydantoin ring and the phenyl ring stand in a similar relationship, while the planes of the phenyl ring and cycloalkane are nearly parallel. These observations are comparable with those commonly observed in cycloalkane-5spirohydantoins and other structurally related compounds. ${ }^{20}$

\section{Crystal packing and intermolecular interactions}

Compounds 1-4 crystallize in the monoclinic space group $P 2_{1} / n$ with $Z=4$. Interaction energies (I.E.s) of the molecular segments extracted from their crystal structures are presented in Table 3. The distance criterion used for the intermolecular interactions is the sum of the van der Waals radii $+0.4 \AA$ and the directionality is greater than $110^{\circ} .^{22}$ Because all four compounds have similar structural features, geometries of segments of 2 as a representative compound are shown in Fig. 3. In all cases, the molecules are centrosymmetrically paired through $\mathrm{N}-\mathrm{H} \cdots \mathrm{O}$ hydrogen bonds (Table 4) to form an $\mathrm{R}_{2}^{2}(8)$ ring (segment I) with the I.E. being about $-74 \mathrm{~kJ} \mathrm{~mol}^{-1}$, wherein the coulombic contribution is more significant than the polarization and dispersion contributions. The formation of these characteristic dimers in 3 and $\mathbf{4}$ is supported by additional bifurcated $\mathrm{C}-\mathrm{H} \cdots \mathrm{O}$ interactions. The dimers then assemble into double chains. Each chain is formed by $\mathrm{C}-\mathrm{H} \cdots \mathrm{O}$ interactions between the carbonyl $\mathrm{O} 1$ atom and the hydrogen atoms of the cycloalkyl and phenyl rings (segment II with an I.E. of about $-34 \mathrm{~kJ} \mathrm{~mol}^{-1}$ which is mainly dominated by the dispersion contribution). The large number of potential donor groups leads to the multifurcated acceptor role of the carbonyl $\mathrm{O} 1$ atom. The $\mathrm{H} \cdots \mathrm{O}$ distance varies between 2.5 and $3.1 \AA$ A, while the "softer" directionality of these interactions ${ }^{23}$ is reflected in a distortion from the linearity with the average $\mathrm{C}-\mathrm{H} \cdots \mathrm{O}$ angle of $130^{\circ}$. The molecules of opposite chains in the successive dimers are joined together by paired $\mathrm{C}-\mathrm{H} \cdots \mathrm{N}$ interactions in a centrosymmetric $\mathrm{R}_{2}^{2}(8)$ pseudo-ring (segment III, I.E. $=c a .-30 \mathrm{~kJ} \mathrm{~mol}^{-1}$ wherein dispersion plays a large role in the stabilization). These interactions are usually regarded as weak hydrogen bonds with structure directing capabilities. ${ }^{24}$ Generally, the hydantoin moieties forming a dimer are separated by $c a .5 .5 \AA$, while the distance between the successive rings is $c a .6 .0 \AA$.

The supramolecular complexity of the investigated compounds arises from the cross-linking of the neighbouring dimers through interactions involving halogens $(\mathrm{X} \cdots \mathrm{O}$ and $\mathrm{C}-$ $\mathrm{H} \cdots \mathrm{X})$ which generate a supramolecular pseudo-hexagonal network (Fig. 4a). While exploring the role of substituents on the cyclohexyl ring in the crystal structure of cyclohexene-5spirohydantoin derivatives, Graus et al. have observed the formation of a 2D network in 4-carboxylic-cyclohexane-5spirohydantoin acid, which also consists of $\mathrm{R}_{6}^{6}(46)$ rings. ${ }^{20 c} \mathrm{In}$ this case, supramolecular rectangles are composed of four coplanar $\mathrm{R}_{2}^{2}(8)$ rings linking the hydantoin moieties and two perpendicular $R_{2}^{2}(8)$ rings formed by the carboxylic groups. This situation opens up the possibility for the formation of a porous structure.

To analyze and compare the corresponding I.E.s, reductions in the halogen bond length relative to the sum of the atomic radii for halogens and oxygen should be taken into account. In the case of the $\mathrm{Br}^{\cdots} \mathrm{O}$ interaction, the larger reduction results in not only a larger coulombic contribution but also a repulsion contribution due to the molecular overlap. The effect of replacing the chloro substituent with the bromo substituent on decomposition of I.E. is somehow more expressed in cyclopentane-5-spirohydantoins than in cyclohexane-5-spirohydantoins. A significant dispersion contribution is needed to achieve the overall stabilization. In segment VI of compounds 1-4 where two $\mathrm{C}-\mathrm{H} \cdots \mathrm{X}$ interactions are also operative, the dispersion contribution exceeds the total energy, thus being a net overcompensation for repulsion.

Regarding the geometry of the $\mathrm{X} \cdots \mathrm{O}$ halogen bonds in segment VI (Table 5), there is a strong preference for a closely linear approach of the carbonyl $\mathrm{O} 2$ acceptor toward the halogen as indicated by the $\mathrm{D}-\mathrm{X} \cdots \mathrm{A}$ angle of $c a \cdot 170^{\circ}$. The angle of approach of the halogen to the carbonyl $\mathrm{O} 2$ atom of $c a$. $120^{\circ}$ reflects that, according to the $\sigma$-hole model, ${ }^{15}$ the $\sigma$-hole of the halogen is attracted to the non-bonding orbitals of the carbonyl oxygen atom. These values are in accordance with those observed in small molecule structures. ${ }^{25}$ The differences in geometric parameters of the halogen bonding in the cyclopentane-5-spirohydantoins (1 and 2) and cyclohexane-5spirohydantoins ( 3 and 4 ) may be attributable to the steric 

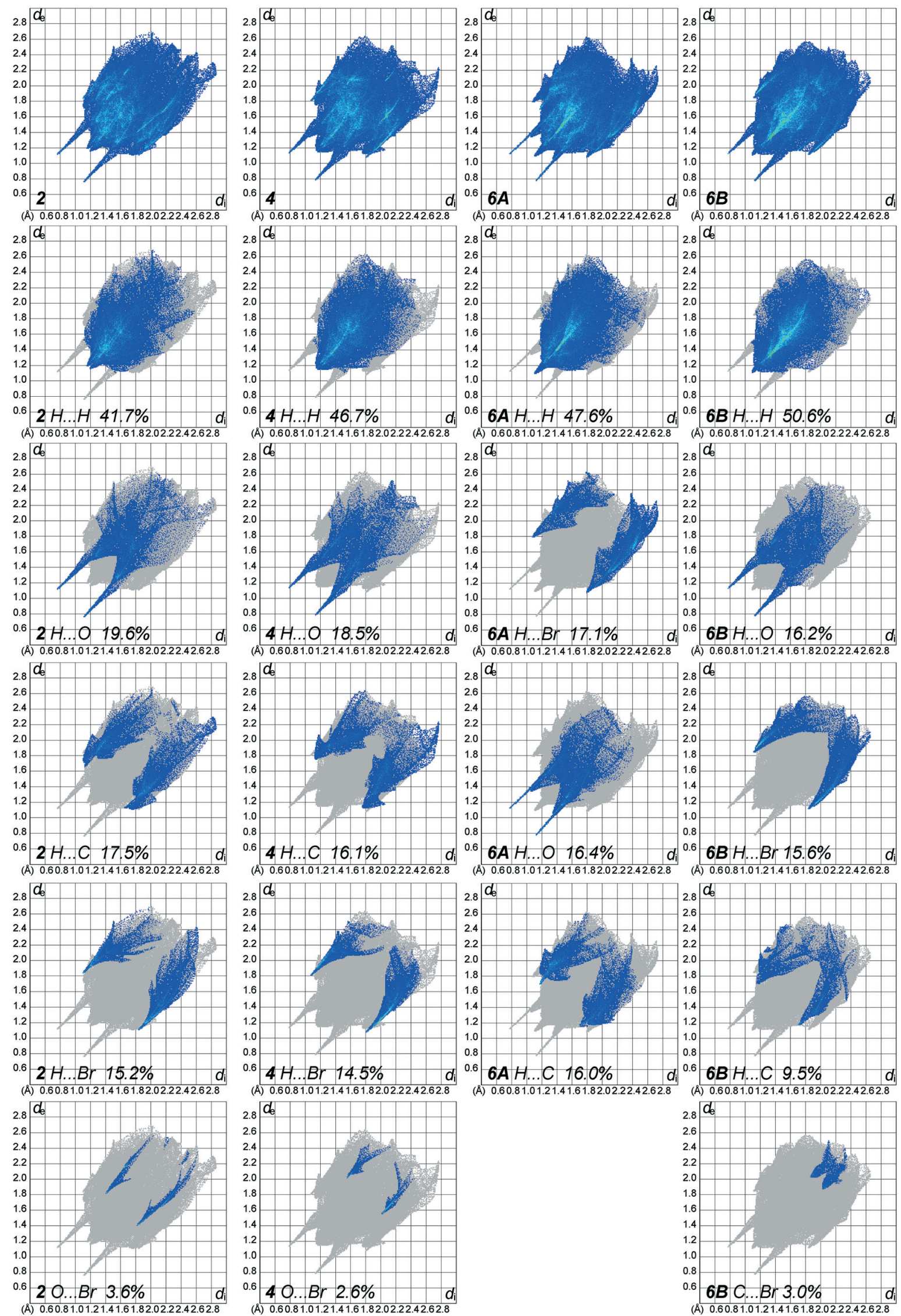

Fig. 7 Fingerprint plots for compounds 2, 4 and 6, decomposed into contributions from specific intermolecular atom-atom contacts. For each plot, the grey shadow is an outline of the complete fingerprint plot. 


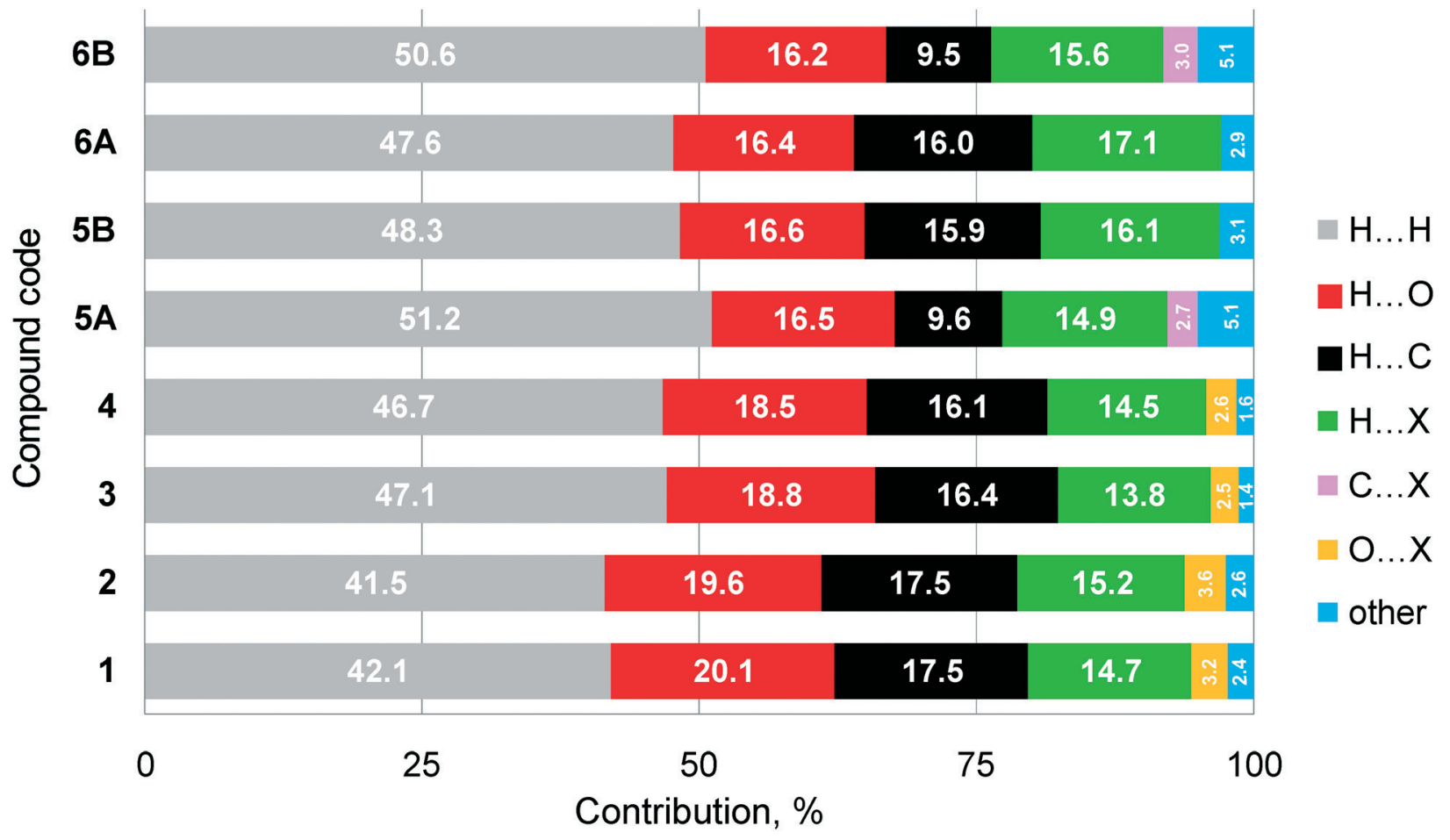

Fig. 8 Relative contribution of intermolecular atom-atom contacts to the Hirshfeld surface area.

interactions between the halogen and the cycloalkyl ring (Table 5). Furthermore, the halogen bond shares the carbonyl $\mathrm{O} 2$ atom with the $\mathrm{C}-\mathrm{H} \cdots \mathrm{O}$ interaction (segment IV) as the common acceptor, while the directions of these interactions are nearly orthogonal to each other. This can be explained by the fact that the non-bonding orbitals of the carbonyl $\mathrm{O} 2$ atom are occupied by this weak hydrogen bond and the only electronegative potential available for halogen bonding comes from the carbonyl $\pi$ orbitals. ${ }^{26}$ In addition to the $\mathrm{C}-$ $\mathrm{H} \cdots \mathrm{O}$ interactions, segment IV (I.E. $\sim-22.6 \mathrm{~kJ} \mathrm{~mol}^{-1}$ ) shows that an interplay of the benzyl groups offers the potential for the $\mathrm{C}-\mathrm{H} \cdots \pi$ interactions. The formation of the network is supported by the $\mathrm{C}-\mathrm{H} \cdots \mathrm{X}$ interactions characterized by distances in the range from 2.9 to $3.1 \AA$ and a slight deviation from linearity $\left(138^{\circ}<\mathrm{C}-\mathrm{H} \cdots \mathrm{X}\right.$ angle $<158^{\circ}$ ) (segments $\mathrm{V}$ and VI). Another molecular pair forms an $\mathrm{R}_{2}^{2}(8)$ pseudo-ring formed via head-to-head $\mathrm{C}-\mathrm{H} \cdots \mathrm{X}$ interactions with $\mathrm{H}^{\cdots} \mathrm{X}$ distances of $3.0 \AA$ and a $\mathrm{C}-\mathrm{H} \cdots \mathrm{X}$ angle of $154.5^{\circ}$, which in the case of compounds 1 and 2 is not planar but has an approximately chair conformation (segment VII, I.E. $\sim-10.5 \mathrm{~kJ}$ $\mathrm{mol}^{-1}$ ). In this way, zigzag chains are generated from alternat-

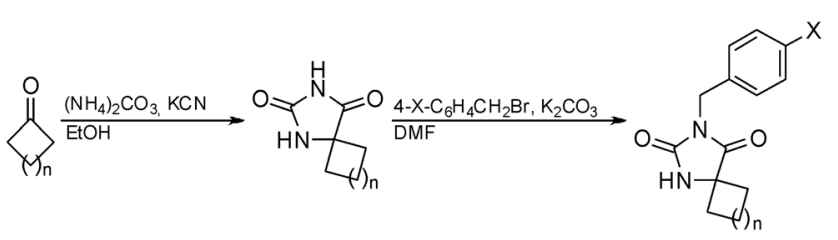

Scheme 1 ing $\mathrm{R}_{2}^{2}(8)$ rings formed by two types of intermolecular interactions, i.e., $\mathrm{N}-\mathrm{H} \cdots \mathrm{O}$ and $\mathrm{C}-\mathrm{H}^{\cdots} \mathrm{X}$ bonds (Fig. $4 \mathrm{~b}$ ). When comparing the chloro derivatives and the bromo derivatives, replacement of the halogen substituent generally affects only the geometry of the $\mathrm{C}-\mathrm{H} \cdots \mathrm{X}$ bonds. The $\mathrm{C}-\mathrm{H} \cdots \mathrm{Br}$ bonds are slightly longer.

Compounds 5 and 6 crystallize with two molecules in the asymmetric unit in the $P \overline{1}$ space group with $Z=4$. A variety of modes of association can be identified in these crystals and we have put emphasis on the intermolecular interactions with I.E. $\geq 10 \mathrm{~kJ} \mathrm{~mol}^{-1}$ (Table 3). Because their structural features are closely related to each other, only geometries of segments extracted from the crystal structure of 6 are presented in Fig. 5. Regarding the modes of association, the analogy can be drawn between molecules $\mathbf{5 A}$ and $\mathbf{6 B}$, as well as $5 \mathrm{~B}$ and 6A. The molecules are linked by $\mathrm{N}-\mathrm{H} \cdots \mathrm{O}$ hydrogen bonds forming two $\mathrm{R}_{2}^{2}(8)$ homodimers (segments I and VII) with I.E.s of -68.3 and $-76.4 \mathrm{~kJ} \mathrm{~mol}^{-1}$ for molecules $6 \mathrm{~A}$ and 6B, respectively; the main contribution to these interactions is a coulombic stabilization. Relative to molecule $6 \mathrm{~A}$, the increase in I.E. for molecule $6 \mathrm{~B}$ comes from the contribution of additional $\mathrm{C}-\mathrm{H} \cdots \mathrm{O}$ interactions (segment VII), thus reflecting their difference in the conformation of the cycloheptyl ring.

Characteristic structural features of compounds 5 and 6 result from the formation of two double chains composed of $\mathrm{R}_{2}^{2}(8)$ rings along the $a$-axis where the principal mode of intermolecular aggregation involves the $\mathrm{C}-\mathrm{H} \cdots \mathrm{O}$ hydrogen bonds between molecules of the same chain including both cycloheptyl and benzyl moieties as weak donors and the carbonyl $\mathrm{O} 1$ atom as an acceptor (segments II, III, VIII and IX). 
Table 7 Crystallographic and refinement data

\begin{tabular}{|c|c|c|c|c|c|c|}
\hline Data & 1 & 2 & 3 & 4 & 5 & 6 \\
\hline Formula & $\mathrm{C}_{14} \mathrm{H}_{15} \mathrm{ClN}_{2} \mathrm{O}_{2}$ & $\mathrm{C}_{14} \mathrm{H}_{15} \mathrm{BrN}_{2} \mathrm{O}_{2}$ & $\mathrm{C}_{15} \mathrm{H}_{17} \mathrm{ClN}_{2} \mathrm{O}_{2}$ & $\mathrm{C}_{15} \mathrm{H}_{17} \mathrm{BrN}_{2} \mathrm{O}_{2}$ & $\mathrm{C}_{16} \mathrm{H}_{19} \mathrm{ClN}_{2} \mathrm{O}_{2}$ & $\mathrm{C}_{16} \mathrm{H}_{19} \mathrm{BrN}_{2} \mathrm{O}_{2}$ \\
\hline Molecular weight/g mol ${ }^{-1}$ & 278.73 & 323.19 & 292.76 & 337.21 & 306.78 & 351.23 \\
\hline Crystal system & Monoclinic & Monoclinic & Monoclinic & Monoclinic & Triclinic & Triclinic \\
\hline Space group & $P 2_{1} / n$ & $P 2_{1} / n$ & $P 2_{1} / n$ & $P 2_{1} / n$ & $P \overline{1}$ & $P \overline{1}$ \\
\hline$T / \mathrm{K}$ & $298(2)$ & $294(2)$ & $295(2)$ & $295(2)$ & $294(2)$ & $298(2)$ \\
\hline$a / \AA$ & $13.453(3)$ & $13.622(3)$ & $13.287(3)$ & $13.505(3)$ & $6.4340(13)$ & $6.4576(13)$ \\
\hline$b / \AA$ & $5.8751(12)$ & $5.9260(12)$ & $5.9132(12)$ & $5.9344(12)$ & $13.594(3)$ & $13.713(3)$ \\
\hline$c / \AA$ & $17.417(4)$ & $17.379(4)$ & $18.536(4)$ & $18.587(4)$ & $18.649(4)$ & $18.624(4)$ \\
\hline$\alpha /{ }^{\circ}$ & 90 & 90 & 90 & 90 & $72.12(3)$ & $72.03(3)$ \\
\hline$\beta / \circ$ & $101.50(3)$ & $101.00(3)$ & $99.09(3)$ & $97.49(3)$ & $84.92(3)$ & $84.97(3)$ \\
\hline$\gamma /{ }^{\circ}$ & 90 & 90 & 90 & 90 & $84.41(3)$ & $84.93(3)$ \\
\hline$V / \AA^{3}$ & $1348.9(5)$ & $1377.1(5)$ & $1438.1(5)$ & $1476.9(5)$ & $1542.0(5)$ & $1559.5(6)$ \\
\hline$Z$ & 4 & 4 & 4 & 4 & 4 & 4 \\
\hline$D_{\mathrm{c}} / \mathrm{g} \mathrm{cm}^{-3}$ & 1.372 & 1.559 & 1.352 & 1.517 & 1.321 & 1.496 \\
\hline$\mu / \mathrm{mm}^{-1}$ & 0.282 & 2.984 & 0.269 & 2.790 & 0.254 & 2.642 \\
\hline$F(000)$ & 584 & 656 & 616 & 688 & 648 & 720 \\
\hline Crystal size/mm & $0.84 \times 0.14 \times 0.07$ & $0.50 \times 0.14 \times 0.10$ & $0.78 \times 0.20 \times 0.12$ & $0.90 \times 0.26 \times 0.07$ & $0.86 \times 0.12 \times 0.08$ & $0.66 \times 0.14 \times 0.10$ \\
\hline$\theta$ range ${ }^{\circ}$ & $3.51-26.73$ & $3.05-26.02$ & $3.45-26.37$ & $3.52-26.37$ & $3.02-26.02$ & $2.99-25.35$ \\
\hline Limiting indices & $\begin{array}{l}-17 \leq h \leq 17 \\
-7 \leq k \leq 7 \\
-22 \leq l \leq 21\end{array}$ & $\begin{array}{l}-14 \leq h \leq 16 \\
-7 \leq k \leq 7 \\
-18 \leq l \leq 21\end{array}$ & $\begin{array}{l}-16 \leq h \leq 16 \\
-7 \leq k \leq 7 \\
-23 \leq l \leq 23\end{array}$ & $\begin{array}{l}-16 \leq h \leq 16 \\
-7 \leq k \leq 7 \\
-23 \leq l \leq 23\end{array}$ & $\begin{array}{l}-7 \leq h \leq 7 \\
-16 \leq k \leq 16 \\
-23 \leq l \leq 23\end{array}$ & $\begin{array}{l}-7 \leq h \leq 7 \\
-13 \leq k \leq 16 \\
-22 \leq l \leq 22\end{array}$ \\
\hline Measured reflections & 11741 & 6989 & 15320 & 15743 & 16450 & 11272 \\
\hline Independent reflections & 2861 & 2715 & 2941 & 3025 & 6044 & 5709 \\
\hline Reflections with $I>2 \sigma(I)$ & 2507 & 2152 & 2461 & 2557 & 4542 & 4135 \\
\hline$R_{\text {int }}$ & 0.0245 & 0.0240 & 0.0281 & 0.0800 & 0.0233 & 0.0238 \\
\hline Final $R$ indices $[I>2 \sigma(I)]$ & $\begin{array}{l}R_{1}=0.0569 \\
\mathrm{w} R_{2}=0.1231\end{array}$ & $\begin{array}{l}R_{1}=0.0389 \\
\mathrm{w} R_{2}=0.0833\end{array}$ & $\begin{array}{l}R_{1}=0.0477 \\
\mathrm{w} R_{2}=0.1109\end{array}$ & $\begin{array}{l}R_{1}=0.0686 \\
\mathrm{w} R_{2}=0.1540\end{array}$ & $\begin{array}{l}R_{1}=0.0566 \\
\mathrm{w} R_{2}=0.1236\end{array}$ & $\begin{array}{l}R_{1}=0.0452 \\
\mathrm{w} R_{2}=0.1222\end{array}$ \\
\hline$R$ indices (all data) & $\begin{array}{l}R_{1}=0.0657 \\
w R_{2}=0.1279\end{array}$ & $\begin{array}{l}R_{1}=0.0553 \\
\mathrm{w} R_{2}=0.0901\end{array}$ & $\begin{array}{l}R_{1}=0.0597 \\
\mathrm{w} R_{2}=0.1173\end{array}$ & $\begin{array}{l}R_{1}=0.0768 \\
\mathrm{w} R_{2}=0.1630\end{array}$ & $\begin{array}{l}R_{1}=0.0807 \\
\mathrm{w} R_{2}=0.1355\end{array}$ & $\begin{array}{l}R_{1}=0.0690 \\
w R_{2}=0.1357\end{array}$ \\
\hline$S$ & 1.107 & 1.023 & 1.071 & 1.174 & 1.049 & 1.068 \\
\hline Parameters & 172 & 172 & 181 & 182 & 379 & 379 \\
\hline$\Delta \rho_{\max }, \Delta \rho_{\min } / \mathrm{e} \AA^{-3}$ & $0.264,-0.311$ & $0.475,-0.493$ & $0.220,-0.363$ & $0.635,-1.634$ & $0.366,-0.256$ & $0.528,-0.586$ \\
\hline
\end{tabular}

Analogously to compounds $\mathbf{1 - 4}$, the $\mathrm{C}-\mathrm{H} \cdots \mathrm{N}$ interactions further stabilize this arrangement of molecules A (segments II and III). Along with these interactions, segment II shows that dimers of molecules $6 \mathrm{~A}$ are linked by paired $\mathrm{C}-\mathrm{H} \cdots \pi$ interactions involving the $\pi$ system of the benzyl group.

Alternatively, the crystal packing of these compounds may be regarded as two double chains (Fig. 6) which are formed from the above-mentioned hydrogen-bonded $\mathrm{R}_{2}^{2}(8)$ homodimers linked through a $\mathrm{C}-\mathrm{H} \cdots \mathrm{X}$ interaction (segment $\mathrm{XI}$ with an I.E. of less than $-10.0 \mathrm{~kJ} \mathrm{~mol}^{-1}$ ). The geometry of these interactions is characterized by a $\mathrm{H}^{\cdots} \mathrm{X}$ distance of $c a$. $3.1 \AA$ and a $\mathrm{C}-\mathrm{H} \cdots \mathrm{X}$ angle of $145^{\circ}$. In the case of molecule $\mathbf{6 B}$, the dimerization of the chains is supported by the headto-head $\mathrm{C}-\mathrm{Br} \cdots \pi$ interaction with an I.E. of $-15 \mathrm{~kJ} \mathrm{~mol}^{-1}$ where the dispersion contribution is the most important (segment $\mathrm{X}$ ). This interaction is characterized by the $\mathrm{Br} \cdots$ centroid distance of $3.943 \AA$ and the distance between both phenyl ring centroids of $4.535 \AA$, which are consistent with the values seen in small molecule structures for the offset parallel stacking orientation with the phenyl ring planes parallel to each other. ${ }^{27}$ The same dimeric segment can also be recognized for molecule 5A. In this case, the shorter $\mathrm{C}-\mathrm{X} \cdots \pi$ distance results in an increase of the coulombic contribution and a slight decrease of repulsion. However, irrespective of the length of the interaction, the dispersion plays the major role here. The neighboring double chains consisting of differ- ent conformers are then cross-linked into a threedimensional framework by the principal action of $\mathrm{C}-\mathrm{H} \cdots \mathrm{O}$ and $\operatorname{lp}(\mathrm{O}) \cdots \pi$ interactions involving the hydantoin $\pi$ system (segments IV and $\mathrm{V}$ with the average I.E. of $34 \mathrm{~kJ} \mathrm{~mol}^{-1}$ ). Regarding the latter interactions, the carbonyl group of one hydantoin ring takes a more or less head-on approach toward the centroid of another hydantoin ring with $\mathrm{O} \cdots$ centroid distances between 3.2 and $3.5 \AA$ A. Segment IV shows adjacent molecules 6A and 6B which adopt an edge-to-face geometry with a $51.1(1)^{\circ}$ dihedral angle between the phenyl rings. Along with the $\mathrm{C}-\mathrm{H} \cdots \mathrm{O}$ interactions, this arrangement enables the $\mathrm{C}-\mathrm{H} \cdots \pi$ interactions. A $\mathrm{C}-\mathrm{H} \cdots \mathrm{X}$ interaction with a $\mathrm{H} \cdots \mathrm{X}$ distance of $3.152 \AA$ and a $\mathrm{C}-\mathrm{H} \cdots \mathrm{X}$ angle $160^{\circ}$ is also cooperative in this sense (segment VI, I.E. $=-10 \mathrm{~kJ} \mathrm{~mol}^{-1}$ ). In the case of molecule $6 \mathrm{~B}$, the neighboring double chains are interconnected through pairs of very weak $\mathrm{C}-\mathrm{H} \cdots \mathrm{X}$ interactions (I.E. $<10 \mathrm{~kJ} \mathrm{~mol}^{-1}$ ); these connections thus form the centrosymmetric rings of $\mathrm{R}_{2}^{2}(8)$ type. On the other hand, their energetic contribution is more significant in the case of molecule 5A (segment VI in Table 3, Fig. S3†). Unlike compounds 1-4, no $\mathrm{X} \cdots \mathrm{O}$ halogen bonding has been identified in the crystal packing of 5 and 6.

Table 6 lists the total lattice energy of the individual compounds in the range from -142 to $-154 \mathrm{~kJ} \mathrm{~mol}^{-1}$ where dispersion, rather than coulombic and polarization, has the major contribution to the total lattice energy. 
The described structural features of the investigated compounds are effectively summarized in the Hirshfeld fingerprint plots (Fig. 7 and $\mathrm{S} 3 \dagger$ ), which provide a single map of all the intermolecular atom-atom interactions. ${ }^{18}$ It can be observed that the patterns of interactions in the investigated compounds are broadly similar. The $\mathbf{H} \cdots \mathrm{H}$ interactions occupy nearly $50 \%$ of the surface area (Fig. 8). Their contribution increases with the increasing size of the cycloalkyl ring, pointing, among others, to the enhanced dispersion terms in the total lattice energies (Table 6). The shortest $\mathrm{H} \cdots \mathrm{H}$ interactions are presented as broad spikes at $d_{\mathrm{e}}+d_{\mathrm{i}} \approx 2.2-2.4 \AA$ where a subtle splitting is observed. It is accepted that this splitting is characteristic for a contact between three atoms, rather than for a direct contact between two atoms. ${ }^{18} \mathrm{~A} \mathrm{sec-}$ ond principal interaction, which accounts from 16 to $20 \%$ of the total number of contacts, results from $\mathrm{H} \cdots \mathrm{O}$ hydrogen bonds. The $\mathrm{N}-\mathrm{H} \cdots \mathrm{O}$ interactions appear as a pair of symmetric spikes extending towards the bottom left $\left(d_{\mathrm{e}}+d_{\mathrm{i}} \approx 1.8 \AA\right.$; the upper spike corresponds to the donor spike, and the lower one is the acceptor spike ${ }^{18}$ ). The investigated crystal structures are further dominated by $\mathrm{H} \cdots \mathrm{C}$ contacts (associated with $\mathrm{C}-\mathrm{H} \cdots \pi$ interactions), which account from 9.5 to $17.5 \%$. This interaction is represented by a pair of wide, well separated wings at $d_{\mathrm{e}}+d_{\mathrm{i}} \approx 2.8-2.9 \AA$.

A characteristic hint towards the $\mathrm{H} \cdots \mathrm{X}$ hydrogen bonds is a pair of broad spikes at longer $d_{\mathrm{i}}$ and $d_{\mathrm{e}}$ (i.e., $d_{\mathrm{e}}+d_{\mathrm{i}} \approx 2.9 \AA$ ) with a greater separation across the diagonal of the plot. ${ }^{18 a}$ These interactions comprise from 13 to $18 \%$ of the surface area. Due to the larger van der Waals radius of the bromine atom, the relative contribution increases slightly in the bromo derivatives when compared to the chloro derivatives with the same cycloalkyl ring. It is also possible to identify other regions of relatively large spot intensity which correspond to intermolecular interactions involving halogens. Around $3 \%$ of the whole surface is associated with the $\mathrm{X} \cdots \mathrm{O}$ bonding in the case of compounds 1-4, while there is a negligible amount in compounds 5 and 6 (up to $0.5 \%$ ). The fingerprint for these interactions resembles the hydrogen bonding patterns. ${ }^{28}$ It is presented as a pair of two sharp spikes at longer $d_{\mathrm{i}}$ and $d_{\mathrm{e}}$ (i.e., $d_{\mathrm{e}}+d_{\mathrm{i}} \approx 3.2-3.6 \AA$ ) which are somehow the longest in compound 2. Analogously to hydrogen bonding, ${ }^{29}$ the stronger the halogen bond, the more elongated the $\mathrm{X} \cdots \mathrm{O}$ spike. Regarding molecules $5 \mathrm{~A}$ and $6 \mathrm{~B}, 3 \%$ of the whole surface can be identified as $\mathrm{X} \cdot \mathrm{C}$ contacts which are referred to as $\mathrm{C}-\mathrm{X} \cdots \pi$ interactions. This feature appears in the diagonal line of the plot at $d_{\mathrm{e}}=d_{\mathrm{i}} \approx 3.8 \AA$. The crystal structures of all the compounds are also described by $\mathrm{X} \cdots \mathrm{X}$ contacts, but they comprise a negligible proportion of the whole surface area. A detailed inspection of the other intermolecular atom-atom contacts has also revealed a negligible contribution of $\mathrm{H} \cdots \mathrm{N}$ and $\mathrm{C} \cdots \mathrm{O}$ (up to $1 \%$ ).

Fig. 3 and 5 contain Hirshfeld surfaces for the molecules in compounds 2 and 6 , which have been mapped over a $d_{\text {norm }}$ range from -0.5 to $1.5 \AA$. This function emphasizes contact distances relative to the sum of van der Waals radii, where the closest contacts are shown in red (negative values of $\left.d_{\text {norm }}\right) .{ }^{18}$ A pair of equally large red spots corresponds to both the donor and the acceptor of $\mathrm{N}-\mathrm{H} \cdots \mathrm{O}$ hydrogen bonds. This is characteristic for the $R_{2}^{2}(8)$ rings. ${ }^{30}$ Additional faint red spots on the Hirshfeld surface of 2 arise from the interactions involving halogens (segment VI, Fig. 3). In the case of compound 6 , the longer $\mathrm{H} \cdots \mathrm{O}$ contacts, which are associated with $\mathrm{C}-\mathrm{H} \cdots \mathrm{O}$ interactions between the carbonyl $\mathrm{O} 2$ atom and the hydrogen atoms of the cycloalkyl and benzyl moieties, show up as two smaller red spots on the Hirshfeld surface (segment IV, Fig. 5). The still longer $\mathrm{H} \cdots \mathrm{O}$ contacts in segment III are characterised by slightly smaller red spots. Regarding the contacts involving halogens, the final faint red spot indicates a short $\mathrm{C}-\mathrm{H} \cdots \mathrm{Br}$ contact. It has been proven that the analysis of the $d_{\text {norm }}$ parameter does not give evidence of the $\mathrm{C}-\mathrm{X} \cdots \pi$ interactions, ${ }^{29}$ which have been identified in the crystal packing of this compound. Generally, the observations based on the Hirshfeld surface analysis are in a good agreement with the results of the PIXEL analysis.

\section{Conclusions}

In this work, a variety of spirohydantoin derivatives has been prepared by the incorporation of a cycloalkyl ring and a substituted benzyl group into the hydantoin ring. This has provided an opportunity to understand the competition and/ or the cooperation of the intermolecular interactions, especially those involving halogens, in the formation of their crystal structures. Although $\mathrm{N}-\mathrm{H} \cdots \mathrm{O}$ hydrogen bonds dominate, weak interactions lead either to stabilization of the crystal structure (regarding the chloro derivatives relative to the bromo derivatives with the same cycloalkyl ring) or to its alteration (regarding compounds 5 and 6 relative to compounds 1-4). It has been recognized that the conformational changes of the cycloheptane ring are also stabilized by $\mathrm{C}-$ $\mathrm{H} \cdots \mathrm{O}$ interactions. The PIXEL model has enabled one to assess the predominance of interaction modes in the investigated crystal structures. Their ranking in descending order is as follows: molecular pairs containing $\mathrm{N}-\mathrm{H} \cdots \mathrm{O}(-63$ to $-77 \mathrm{~kJ}$ $\left.\mathrm{mol}^{-1}\right)>$ molecular pairs containing $\mathrm{C}-\mathrm{H} \cdots \mathrm{N}\left(\sim 30 \mathrm{~kJ} \mathrm{~mol}^{-1}\right)$ $>$ molecular pairs containing $\mathrm{C}-\mathrm{H} \cdots \mathrm{O}\left(-22\right.$ to $\left.-34 \mathrm{~kJ} \mathrm{~mol}^{-1}\right)$ $>$ molecular pairs containing interactions with halogens (-19 to $-15 \mathrm{~kJ} \mathrm{~mol}^{-1}$ ). According to Hirshfeld analysis, the close contacts are dominated by those associated with relatively weak interactions. Considering diverse pharmaceutical applications of hydantoin derivatives, our investigation of the role of intermolecular interactions involving halogens allows them to be incorporated into strategies for designing new biologically active compounds as well as bio-inspired materials.

\section{Experimental}

Cycloalkane-5-spirohydantoins were synthesized by the method of Bucherer ${ }^{31}$ and further alkylated at position 3 using the corresponding benzyl halide in $\mathrm{K}_{2} \mathrm{CO}_{3} / \mathrm{N}, \mathrm{N}$ dimethylformamide (Scheme 1). ${ }^{32}$ The molecular structures 
and the purities of the synthesized compounds were confirmed by melting points, elemental analysis, FTIR, and ${ }^{1} \mathrm{H}$ and ${ }^{13} \mathrm{C}$ NMR spectroscopy (ESI, $\dagger$ Fig. S5-S16). Elemental analysis was realized using an Elemental Vario EL III microanalyzer. FTIR spectra were recorded on a Bomem MB 100 spectrophotometer. ${ }^{1} \mathrm{H}$ and ${ }^{13} \mathrm{C}$ NMR spectral measurements were performed using a Bruker AC 200 spectrometer at 200 $\mathrm{MHz}$ for the ${ }^{1} \mathrm{H}$ NMR and $50 \mathrm{MHz}$ for the ${ }^{13} \mathrm{C}$ NMR spectra.

\section{X-ray structure determination}

Single crystals suitable for X-ray structure determination were obtained by slow evaporation of acetonitrile solutions at room temperature. Single-crystal X-ray diffraction data were collected using an Oxford Gemini S diffractometer equipped with a sapphire3 CCD detector, with monochromatized Mo $K \alpha$ radiation $(\lambda=0.71073 \AA)$. Intensities were corrected for absorption by means of analytical ( 1 and 4), multi-scan (2, 3, and 5) and Gaussian (6) methods. The structures were solved by direct methods (SIR92 ${ }^{33}$ ) and refined on $F^{2}$ by full-matrix least-squares using the programs SHELXL-97, ${ }^{34}$ SHELXL$2014 / 7^{35}$ and WinGX. ${ }^{36}$ All non-hydrogen atoms were refined anisotropically. The positions of $\mathrm{H}$ atoms connected to $\mathrm{C}$ atoms were calculated on geometric criteria and refined by the riding model with $U_{\text {iso }}=1.2 U_{\text {eq }}(\mathrm{C})$. Selected crystal data and refinement results for 1-6 are listed in Table 7 .

\section{Computational methods}

A detailed crystal packing analysis on the title compounds was performed using the PIXELC module ${ }^{19}$ from the CLP computer program package (version 12.5.2014). Coulombic energies calculated by PIXEL are as accurate as those obtained by rigorous evaluation by quantum mechanics, while the method allows a consistent and reliable parametric estimation of dispersion and repulsion contributions to interaction energies. The lattice energies of the compounds were calculated and the total energy is partitioned into their coulombic, polarization, dispersion and repulsion contributions. Molecular structures for PIXEL analysis are extracted from the $\mathrm{X}$-ray structures, with hydrogen atoms relocated to their usual values $(\mathrm{C}-\mathrm{H}$ distance $1.08 \AA$, $\mathrm{O}-\mathrm{H}$ and $\mathrm{N}-\mathrm{H}$ distance $1.00 \AA)$. The molecular electron densities for PIXEL energy calculations were derived at the MP2/6-31G(d,p) level using the Gaussian 09 program package. ${ }^{37}$ Hirshfeld surfaces ${ }^{18}$ and the associated 2D-fingerprint plots ${ }^{18 b}$ were generated using CrystalExplorer 3.1. ${ }^{38}$ Hirshfeld surfaces mapped with different properties, e.g. $d_{\mathrm{e}}, d_{\text {norm }}$, shape index, curvedness, have proven to be a useful visualization tool for the analysis of intermolecular interactions and the crystal packing behavior of the molecules. ${ }^{18} d_{\mathrm{i}}$ and $d_{\mathrm{e}}$ are functions of distances from the Hirshfeld surface to the nearest nucleus inside the surface and outside the surface, respectively, while $d_{\text {norm }}$ combines both $d_{\mathrm{e}}$ and $d_{\mathrm{i}}$, each normalised by the van der Waals radius for the particular atoms involved in close contact with the surface. ${ }^{18}$ The 2D fingerprint plots were constructed using $d_{\mathrm{i}}$ and $d_{\mathrm{e}}$ in the translated 0.4-3.0 $\AA$ range. The 2D fin- gerprint plot provides decomposition of the Hirshfeld surfaces into contribution of different intermolecular interactions in the crystal structure. Therefore, both Hirshfeld surfaces and fingerprint plots enable the comparison of intermolecular interactions which build different supramolecular structures.

\section{Acknowledgements}

This work was supported by the Ministry of Education, Science and Technological Development of the Republic of Serbia (Project no. 172013, 172035 and III45007).

\section{Notes and references}

1 C. R. Groom and F. H. Allen, Angew. Chem., Int. Ed., 2014, 53, 662.

2 A. J. Cruz-Cabeza and C. H. Schwalbe, New J. Chem., 2012, 36, 1347.

3 B. LeDuc, Antiseisure agent, In: Foye's principles of medicinal chemistry, ed. T. Lemke and D. Williams, Lippincott Williams \& Wilkins, Philadelphia, PA, 6th edn, 2008.

4 A. S. Troupin, P. Friel, M. P. Lovely and A. J. Wilensky, Ann. Neurol., 1979, 6, 410.

5 W. D. Hooperer, N. J. Oshea and M. S. Qing, Chirality, 1992, 4, 142.

6 (a) J. Handzlik, M. Bajda, M. Zygmunt, D. Maciag, M. Dybała, M. Bednarski, B. Filipek, B. Malawska and K. KiećKononowicz, Bioorg. Med. Chem., 2012, 20, 2290; (b) N. Singh, J. N. Sinha, S. K. Rastogi, P. R. Dua and R. P. Kohli, Jpn. J. Pharmacol., 1971, 21, 755; (c) D. Bracchetti, F. Naccarella, M. Palmieri, M. Fulvi and P. C. Pavesi, J. Cardiovasc. Pharmacol., 1989, 14, S79.

7 (a) F. Fujisaki, K. Toyofuku, M. Egami, S. Ishida, N. Nakamoto, N. Kashige, F. Miake and K. Sumoto, Chem. Pharm. Bull., 2013, 61, 1090; (b) J. Handzlika, E. Szymańska, S. Alibert, J. Chevalier, E. Otrębska, E. Pękala, J.-M. Pagès and K. Kieć-Kononowicz, Bioorg. Med. Chem., 2013, 21, 135.

8 (a) G. Spengler, M. Evaristo, J. Handzlik, J. Serly, J. Molnár, M. Viveiros, K. Kieć-Kononowicz and L. Amaral, Anticancer Res., 2010, 30, 4867; (b) H. A. Mohamed, N. M. R. Girgis, R. Wilcken, M. R. Bauer, H. N. Tinsley, B. D. Gary, G. A. Piazza, F. M. Boeckler and A. H. Abadi, J. Med. Chem., 2011, 54, 495; (c) M. Mudit, F. A. Behery, V. B. Wali, P. W. Sylvester and K. A. El Sayed, Nat. Prod. Commun., 2010, 5, 1623.

9 (a) A. Camerman and N. Camerman, Science, 1970, 168, 1457; (b) G. P. Jones and P. R. Andrews, J. Chem. Soc., Perkin Trans. 2, 1987, 415; (c) M. L. Brown, G. B. Brown and W. J. Brouillette, J. Med. Chem., 1997, 40, 602.

10 G. M. Lipkind and H. A. Fozzard, Mol. Pharmacol., 2010, 78, 631.

11 G. R. Desiraju, Chem. Commun., 1997, 1475.

12 A. Gavezzotti and L. L. Presti, Cryst. Growth Des., 2016, 16, 2952.

13 G. R. Desiraju, Acc. Chem. Res., 2002, 35, 565. 
14 A. Kovács and Z. Varga, Coord. Chem. Rev., 2006, 250, 710.

15 (a) P. Politzer, J. S. Murray and T. Clark, Phys. Chem. Chem. Phys., 2010, 12, 7748; (b) X. Ding, M. Tuikka and M. Haukka, Halogen Bonding in Crystal Engineering, in Recent Advances in Crystallography, ed. J. B. Benedict, In Tech, New York, 2012, p. 143.

16 K. E. Riley and P. Hobza, Phys. Chem. Chem. Phys., 2013, 15, 17742.

17 P.-P. Zhou, W.-Y. Qiu, S. Liub and N.-Z. Jin, Phys. Chem. Chem. Phys., 2011, 13, 7408.

18 (a) M. A. Spackman and D. Jayatilaka, CrystEngComm, 2009, 11, 19; (b) M. A. Spackman and J. J. McKinnon, CrystEngComm, 2002, 4, 378; (c) J. J. McKinnon, M. A. Spackman and A. S. Mitchell, Acta Crystallogr., Sect. B: Struct. Sci., 2004, 60, 627; (d) S. K. Seth, D. Sarkar and T. Kar, CrystEngComm, 2011, 13, 4528; (e) D. A. Safin, K. Robeyns and Y. Garcia, CrystEngComm, 2016, 18, 7284.

19 (a) A. Gavezzotti, Molecular Aggregation, Oxford University Press, Oxford, 2005, ch. 12; (b) A. Gavezzotti, J. Phys. Chem. B, 2003, 107, 2344; (c) A. Gavezzotti, Mol. Phys., 2008, 106, 1473.

20 (a) B. Chattopadhyay, A. K. Mukherjee, N. Narendra, H. P. Hemantha, V. V. Sureshbabu, M. Helliwell and M. Mukhherjee, Cryst. Growth Des., 2010, 10, 4476; (b) S. Graus, S. Uriel and J. L. Serrano, CrystEngComm, 2012, 14, 3759; (c) S. Graus, D. Casabona, S. Uriel, C. Cativiela and J. L. Serrano, CrystEngComm, 2010, 12, 3132; (d) P. T. Todorov, R. N. Petrova, E. D. Naydenova and B. L. Shivachev, Cent. Eur. J. Chem., 2009, 7, 14.

21 S. Hmuda, N. Trišović, J. Rogan, D. Poleti, Ž. Vitnik, V. Vitnik, N. Valentić, B. Božić and G. Ušćumlić, Monatsh. Chem., 2014, 145, 821.

22 (a) I. Dance, New J. Chem., 2003, 1, 22; (b) D. Dey, C. S. Shripanavar, K. Banerjee and D. Chopra, J. Crystallogr., 2014, DOI: $10.1155 / 2014 / 585282$.

23 Y. Gu, T. Kar and S. Scheiner, J. Am. Chem. Soc., 1999, 121, 9411.

24 (a) H. Masu, Y. Sagara, F. Imabeppu, H. Takayanagi, K. Katagiri, M. Kawahata, M. Tominaga, H. Kagechika, K. Yamaguchia and I. Azumaya, CrystEngComm, 2011, 13, 406; (b) A. J. Cruz Cabeza, G. M. Day, W. D. S. Motherwell and W. Jones, Cryst. Growth Des., 2006, 6, 1858; (c) F. H. Allen, C. M. Bird, R. S. Rowland, S. E. Harris and C. H. Schwalbe, Acta Crystallogr., Sect. B: Struct. Sci., 1995, 51, 1068.
25 C. Ouvrard, J.-Y. Le Questel, M. Berthelot and C. Laurence, Acta Crystallogr., Sect. B: Struct. Sci., 2003, 59, 512.

26 (a) A. R. Voth, P. Khuu, K. Oishi and P. S. Ho, Nat. Chem., 2009, 1, 74; (b) M. R. Scholfield, C. M. Vander Zanden, M. Carter and P. S. Ho, Protein Sci., 2013, 22, 139.

27 H. Matter, M. Nazar, S. Güssregen, D. W. Will, H. Schreuder, A. Bauer, M. Urmann, K. Ritter, M. Wagner and V. Wehner, Angew. Chem., Int. Ed., 2009, 48, 2911.

28 A. J. Rybarczyk-Pirek, L. Checinska, M. Malecka and S. Wojtulewski, Cryst. Growth Des., 2013, 13, 3913.

29 A. J. Rybarczyk-Pirek, M. Łukomska-Rogala, S. Wojtulewski and M. Palusiak, Cryst. Growth Des., 2015, 15, 5802.

30 Y.-H. Luo and B.-W. Sun, CrystEngComm, 2013, 15, 7490.

31 H. T. Bucherer and V. A. Lieb, J. Prakt. Chem., 1934, 141, 5.

32 H. Suzuki, M. B. Kneller, D. A. Rock, J. P. Jones, W. F. Trager and A. E. Rettie, Arch. Biochem. Biophys., 2004, 429, 1.

33 A. Altomare, G. Cascarano, C. Giacovazzo, A. Guagliardi, M. C. Burla, G. Polidori and M. Camalli, J. Appl. Crystallogr., 1994, 27, 435.

34 G. M. Sheldrick, Acta Crystallogr., Sect. A: Found. Crystallogr., 2008, 64, 112.

35 G. M. Sheldrick, Acta Crystallogr., Sect. C: Struct. Chem., $2015,71,3$.

36 L. J. Farrugia, J. Appl. Crystallogr., 2012, 45, 849.

37 M. J. Frisch, G. W. Trucks, H. B. Schlegel, G. E. Scuseria, M. A. Robb, J. R. Cheeseman, G. Scalmani, V. Barone, B. Mennucci, G. A. Petersson, H. Nakatsuji, M. Caricato, X. Li, H. P. Hratchian, A. F. Izmaylov, J. Bloino, G. Zheng, J. L. Sonnenberg, M. Hada, M. Ehara, K. Toyota, R. Fukuda, J. Hasegawa, M. Ishida, T. Nakajima, Y. Honda, O. Kitao, H. Nakai, T. Vreven, J. A. Montgomery Jr, J. E. Peralta, F. Ogliaro, M. Bearpark, J. J. Heyd, E. Brothers, K. N. Kudin, V. N. Staroverov, R. Kobayashi, J. Normand, K. Raghavachari, A. Rendell, J. C. Burant, S. S. Iyengar, J. Tomasi, M. Cossi, N. Rega, J. M. Millam, M. Klene, J. E. Knox, J. B. Cross, V. Bakken, C. Adamo, J. Jaramillo, R. Gomperts, R. E. Stratmann, O. Yazyev, A. J. Austin, R. Cammi, C. Pomelli, J. W. Ochterski, R. L. Martin, K. Morokuma, V. G. Zakrzewski, G. A. Voth, P. Salvador, J. J. Dannenberg, S. Dapprich, A. D. Daniels, Ö. Farkas, J. B. Foresman, J. V. Ortiz, J. Cioslowski and D. J. Fox, Gaussian 09, Revision D.01, Gaussian Inc., Wallingford, CT, 2009.

38 S. K. Wolff, D. J. Grimwood, J. J. McKinnon, M. J. Turner, D. Jayatilaka and M. A. Spackman, CrystalExplorer (Version 3.1), University of Western Australia, 2012. 